\title{
The effect of stimulus duration on over-selectivity: Evidence for the role of within-compound associations
}

\author{
Gemma Reynolds \\ Middlesex University, UK \\ Phil Reed \\ Swansea University, UK
}

\begin{abstract}
Author Notes
Gemma Reynolds, Department of Psychology, Middlesex University, United Kingdom; Phil Reed, Department of Psychology, Swansea University, United Kingdom.

Correspondence concerning this article should be addressed to Gemma Reynolds, Department of Psychology, Middlesex University, The Burroughs, Hendon, London, NW4 4BT. Email: g.reynolds@mdx.ac.uk
\end{abstract}




\begin{abstract}
The phenomenon whereby behaviour becomes controlled by one aspect of the environment at the expense of other aspects of the environment (stimulus over-selectivity) is widespread across many intellectual and developmental disabilities. However, the theoretical mechanisms underpinnings over-selectivity are not understood. Given similarities between over-selectivity and overshadowing, exploring over-selectivity using associative learning paradigms might allow better theoretical understanding of the phenomenon. Three experiments explored over-selectivity using a simultaneous discrimination task with typically developing participants undergoing a cognitively demanding task. Experiment 1 investigated whether stimulus duration effects found within the overshadowing literature also occurred in an over-selectivity paradigm, and demonstrated that greater over-selectivity was observed when stimuli were presented for short durations ( $2 \mathrm{~s}$ and $5 \mathrm{~s}$ ) compared to longer durations (10s). Experiment 2 demonstrated that a post-training revaluation procedure resulted in retrospective revaluation for stimuli presented at shorter durations $(2 \mathrm{~s})$ and mediated extinction for stimuli presented at longer durations (10s). Such results replicate findings from the overshadowing literature that have been interpreted in terms of within-compound associations while also supporting assumptions made by an extended comparator hypothesis. Experiment 3 uses an additional control condition to further demonstrate that the retrospective revaluation is a genuine revaluation effect. Additionally, the experiment provides further evidence for the within-compound association explanation of the results through manipulating the consistency with which elements of a compound were paired during training. Taken together, the findings highlight the necessity to consider the role of withincompound associations in over-selectivity, allowing for a better understanding of overselectivity effects. Keywords: Stimulus over-selectivity, stimulus duration, posttraining revaluation, within-compound associations
\end{abstract}


Running Head: STIMULUS OVER-SELECTIVITY AND CS DURATION

'Stimulus over-selectivity' or 'restricted stimulus control' (e.g., Dube \& McIlvane, 1997) refers to a widespread clinical phenomenon in which behaviour is controlled by one element of the environment at the expense of other aspects of the environment, limiting the breadth of stimulus control (see Dube, 2009 for a review). The over-selectivity effect is observed across many disabilities, including Autism Spectrum Disorders (ASD; Hedbring \& Newsom, 1985; Koegel \& Wilhelm, 1973; Lovaas \& Schreibman, 1971; Schreibman \& Lovaas, 1973), learning disabilities (Bailey, 1981; Gersten, 1983; Schneider \& Salzberg, 1982; Wilhelm \& Lovaas, 1976), acquired neurological damage (Wayland \& Taplin, 1982, 1985), as well as in the elderly (Kelly, Leader, \& Reed, 2016; McHugh \& Reed, 2007). Over-selectivity has also been observed in intellectually typical adults undergoing high cognitive demands, or a concurrent and distracting activity (Broomfield, McHugh, \& Reed, 2008a, 2008b; 2010; Reynolds \& Reed, 2011a, 2011b, 2012).

Experimentally, stimulus over-selectivity has been explored using compound discrimination learning procedures, including simultaneous discrimination (Lovaas et al., 1971), and match-to-sample (e.g., Dube \& McIlvane, 1997). In simultaneous discrimination procedures, participants are trained through trial-and-error to select a complex stimulus involving at least two elements $(\mathrm{AB}+)$ over an alternative two-element compound ( $\mathrm{CD}-)$. Once discriminative control is established, the elements from the previously reinforced compound $(\mathrm{AB})$ are presented individually in extinction along with an element from the previously nonreinforced compound (CD: i.e., A vs C, A vs D, B vs C, and B vs D). Overselectivity occurs if one element from the previously reinforced compound (either A or B) is responded to a greater level than the other. The stimuli that become over-selected, and, thus, control behaviour, are not necessarily more predictive cues, but can be insignificant features of a complex array of stimuli (e.g., Lovaas, Schreibman, Koegel \& Rehm, 1971). Separate components tend to be selected equally in typically developing populations, whereas 
individuals in many cognitively-challenged populations tend to over-select one element at the expense of other elements (e.g., Dube \& McIlvane, 1997, 1999; Koegel \& Wilhelm, 1973; Lovaas \& Schreibman, 1971; Schreibman \& Lovaas, 1973; Wilhelm \& Lovaas, 1976). Therefore, procedurally, over-selectivity can be defined as significantly more responding to $\mathrm{A}$ after $\mathrm{AB}+\mathrm{CD}$ - compared to $\mathrm{B}$ after $\mathrm{AB}+\mathrm{CD}-$.

On the face of it, over-selectivity has much in common with the more-often studied and better theoretically-understood phenomenon of overshadowing (e.g., Pavlov, 1927). Overshadowing refers to the phenomenon that occurs following the presentation of a compound consisting of two elements when it is immediately followed by a biologically significant outcome. The compound reinforcement results in the two cues competing for behavioural control and subsequently results in the overshadowing effect; less responding is shown for the elements when presented alone following compound training, compared to if they were trained alone as individual elements (i.e., less responding to $\mathrm{X}$ after $\mathrm{AX}+$ than to $\mathrm{X}$ after $\mathrm{X}+$ ). Overshadowing also includes the possibility of reciprocal overshadowing, in which $\mathrm{AX}+$ training results in less responding to both $\mathrm{X}$ and $\mathrm{A}$, relative to that following $\mathrm{X}+$ and $\mathrm{A}+$, respectively.

Given the similarity between overshadowing and over-selectivity, it may be the case that further exploring the mechanisms responsible for over-selectivity using associative learning paradigms, might allow a better theoretical understanding of over-selectivity effects (Lovaas et al., 1971; Reed, 2011). However, there are a number of operational distinctions between over-selectivity and overshadowing that are important to note, and which may mean that such similarities do not operate at the level of mechanism. For example, during training in an over-selectivity procedure, a reinforced compound is presented simultaneously with a non-reinforced compound ( $\mathrm{AB}+$ and $\mathrm{CD}-)$ with more responding to $\mathrm{A}$ than to $\mathrm{B}$ indicating over-selectivity. Thus, over-selectivity is defined by the relative relationship of the control 
acquired by elements $\mathrm{A}$ and $\mathrm{B}$ after simultaneous discrimination training, whereas overshadowing is defined by reference to a reduced amount of control exerted by one stimulus $(\mathrm{X})$ from the compound $(\mathrm{AX}+)$, relative to the control exerted when that element is conditioned individually $(\mathrm{X}+)$. Thus, while the adoption of perspectives developed for overshadowing may help, it is unclear whether they would automatically apply to overselectivity procedures, and this extension would help develop a theoretical understanding of over-selectivity.

Moreover, recently, Maes and colleagues (2016) questioned the generality of cue competition phenomena by documenting 15 experiments that failed to find evidence for a blocking effect (the finding of impaired learning of a CS-US association if the CS is presented simultaneously during conditioning with a different CS that has already been associated with the US; Kamin, 1969). Given that cue competition phenomena are therefore under scrutiny, research exploring the procedural variables and boundary conditions under which these effects are observed, and potential mediating mechanisms, is fundamental. Indeed, several manipulations have been used to understand the underlying mechanisms of overshadowing (see Wheeler \& Miller, 2008 for a review) and these manipulations have direct relevance for understanding the potential mechanisms of over-selectivity. However, to date, research has only explored a small number of these manipulations in the context of over-selectivity, for example, partial as opposed to continuous reinforcement schedules (Reynolds \& Reed 2011b) and trace as opposed to delayed conditioning procedures (Gibson \& Reed, 2005).

Traditionally, over-selectivity has been understood as a deficit in attention (e.g., Dube, 2009; Dube, Lombard, Farren, Flusser, Balsamo \& Fowler, 1999; Dube \& McIlvane, 1999; Koegel \& Schreibman, 1977; Koegel \& Wilhelm, 1973; Lovaas \& Schreibman, 1971; Lovaas et al., 1971; Reed, Hawthorn, Bolger, Meredith, \& Bishop, 2012) or encoding (e.g., 
Boucher \& Warrington, 1976; Reed \& Gibson, 2005). That is, the individual fails to attend to all elements of the stimulus during initial training. If only certain elements are attended to, only these elements can subsequently acquire control over behaviour. More recently, research has suggested that all stimuli are attended to and encoded, and that initial learning is intact, but that individuals showing over-selectivity fail to be able to retrieve the full range of stimuli that best predict future events, and, hence, which stimuli should be responded to in order to control behaviour (see Broomfield et al., 2008a, 2010; Leader, Loughnane, McMoreland \& Reed, 2009; Reed, 2011; Reed, Broomfield, McHugh, McCausland, \& Leader, 2009). A variant of the comparator hypothesis (e.g., Denniston, Savastano, \& Miller, 2001; Matzel, Schachtman, \& Miller, 19851985; Miller \& Matzel, 1988; Miller \& Schachtman, 1985) provides a possible explanation for a post-acquisition view of overselectivity. Such a perspective assumes that all stimuli present on a target-outcome trial will acquire a degree of strength and that a memory or representation of learning is activated following the presentation of a previously learned-about target stimulus. This triggers a comparator mechanism which indirectly activates other stimuli that were learned about in the existence of the target stimulus. At the time of performance, a comparator process compares the strengths of both the directly and indirectly learned-about representations in order to determine the level of conditioned responding. That is, the comparator mechanism is more likely to select the stimuli with stronger predictive value to control behaviour (Miller \& Schachtman, 1985; Reed, 2011).

Within an overshadowing context, research has demonstrated that longer duration CS presentations in elemental training, attenuate conditioned responding (e.g., Gibbon \& Balsam, 1981; Sissons, Urcelay, \& Miller, 2009), often referred to as the CS-duration effect (see Urcelay, 2017). Crucially, more recent research (e.g., Urushihara, Stout, \& Miller, 2004; Sissons et al., 2009; Urushihara \& Miller, 2007; Westbrook, Homewood, Horn, \& Clarke, 
1983) demonstrated that with compound cue training, short CS durations resulted in overshadowing whereas longer CS durations resulted in no cue competition (the opposite as is true for elemental cue training). The extended comparator hypothesis can account for this effect by suggesting that during elemental training, longer durations result in a strong CS(A)$\mathrm{CS}(\mathrm{X})(\mathrm{CS}$ and context) association consequently enhancing the potential for the context to act as a first-order comparator. However, longer durations CSs during compound training result in strong within-compound associations both between the target CS and the overshadowing CS, as well as between the target CS and the context, resulting in the context acting as a second-order comparator stimulus. At test, the target CS and context compete in their roles as comparators, reducing the effectiveness of the overshadowing CS as a firstorder comparator stimulus, whilst the overshadowing CS (as a second-order comparator), attenuates the effectiveness of the context as a first-order comparator. Following short stimulus durations, the context is less effective at reducing the effectiveness of the overshadowing CS to compete with the target and so cue competition if observed. As a result, the CS duration and overshadowing counteract each other (see Wheeler \& Miller, 2008).

Given the above considerations, the current three studies aim to investigate the effects of stimulus duration on the presence of over-selectivity. Stimulus duration effects have already been demonstrated within the overshadowing literature and extending such findings to an over-selectivity paradigm (i.e., using a simultaneous discrimination task; a distinctly different procedure to that of overshadowing) would allow a greater understanding of overselectivity with reference to the role of within-compound associations. Additionally, the second experiment aims to delineate between various theories of over-selectivity that rely on within-compound associations by investigating the effects of post-training revaluation at short and long stimulus durations. The third experiment extends this by discrediting a trace 
decay interpretation of the revaluating findings while providing further support for a withincompound association interpretation by varying the consistency with which the elements of a compound are paired during training.

\section{Experiment 1}

The first experiment explored the effect of stimulus durations within an overselectivity paradigm. As would be expected by the comparator perspective, it was predicted that less over-selectivity would be found following longer CS durations (10s) whilst overselectivity would be more prominent following shorter CS durations (2s). This is because following short stimulus durations, over-selectivity occurs as the context does not become a second-order comparator stimulus. However, with the longer stimulus duration, the context and the target stimulus effectively cancel each other out (the counteraction effect) reducing competition at test.

\section{Method}

\section{Participants}

Eighty-four volunteer participants ( 29 male; 55 female) were recruited from the general public and university students. Participants had an age range of 19 to 34 years $(M=$ 20.70 years, $S D=2.38$ ), due to McHugh and Reed's (2007) research on age trends in overselectivity, participants under the age of 18 and over the age of 55 were excluded. A priori power analysis ( $\mathrm{G}^{*}$ Power; Faul, Erdfelder, Lang, \& Buchner, 2007) for the overall analysis of variance (ANOVA) indicated that this was sufficient sample size to detect medium effect sizes. 
Running Head: STIMULUS OVER-SELECTIVITY AND CS DURATION

Participants were randomly assigned to one of three stimulus durations; $2 \mathrm{~s}(\mathrm{~N}=28), 5 \mathrm{~s}$ $(\mathrm{N}=28)$, or $10 \mathrm{~s}(\mathrm{~N}=28)$. Within each of these stimulus duration groups, participants were further divided into one of two groups; half of the participants received a cognitive load ('Load' groups), and the other half of the participants did not receive a cognitive load ('No Load' groups). Those receiving a cognitive load were required to vocally count backwards in sevens from a random five-digit number throughout the entire experiment as the concurrent cognitive load generates over-selectivity in non-clinical participants (see Reed \& Gibson, 2005; Reynolds \& Reed, 2011). If participants hesitated, they were prompted to continue counting. Those not receiving a cognitive load were not required to count. Thus, there were six groups in total receiving either $2 \mathrm{~s}, 5 \mathrm{~s}$, or $10 \mathrm{~s}$ CS durations, and either a cognitive task (Load) or no cognitive task (No Load), with 14 participants in each group.

\section{Materials}

Autism Spectrum Quotient (AQ: Baron-Cohen et al., 2001). As the presence of existing ASD traits would confound the results, all participants completed the AQ to assess pre-existing high functioning ASD. It was anticipated that all participants scoring over 32 would be excluded from the analysis. However, no participants scored this high and therefore no exclusions were made.

Compound and Elemental Stimuli. Stimuli used during the procedure included 8 abstract pictorial symbols taken from various fonts from Microsoft Word 2010 (Wingdings, Wingdings 2 and Symbol). Stimuli were either presented as a compound for training or an elemental stimulus during testing. Participants received different symbols for each stimulus to control for saliency effects, and systematic randomization determined the position of the stimuli. Additionally, the symbols have been successfully used in previous research using a similar over-selectivity paradigm with no evidence of differing a-priori salience (e.g., Reed, 
Reynolds, \& Fermandel, 2012; Reynolds \& Reed, 2011b, 2012). In all phases, each symbol appeared in black and measured approx. $5 \mathrm{~cm} \times 5 \mathrm{~cm}($ see Figure 1).

Figure 1 about here

\section{Procedure}

After completing the AQ by hand, the remaining procedure was automated on a Dell Latitude E6540 laptop (display size: 15.5”), programmed in e-prime by the first author. Table 1 depicts the procedure used.

Training Phase. Training commenced with the instructions 'Please select one of the two cards presented as soon as 'respond now' appears on the screen. You will be given feedback indicating whether you selected the correct or incorrect card. Your aim is select the correct card. If you have been instructed to count backwards then you should begin counting backwards now and press Next'. Participants in the groups receiving a cognitive load were told to begin counting.

All participants were then presented with two simple discrimination tasks consisting of the compound stimuli ( $\mathrm{AB}$ vs $\mathrm{CD}, \mathrm{EF}$ vs $\mathrm{GH})$. The tasks were interspersed so that compound stimulus $\mathrm{AB}$ appeared on the screen paired with compound stimulus $\mathrm{CD}$ intermixed with trials of compound stimulus EF paired with compound stimulus GH (see Figure 1 to demonstrate an $\mathrm{AB}$ vs $\mathrm{CD}$ trial). All participants received different symbols for each stimulus to control for the effects of intrinsic salience of the elements.

Participants selected one of the compounds when 'Respond Now' appeared on the screen by clicking the mouse cursor on one of the compounds. The 'Respond Now' instructions appeared after the trial had been presented for $2 \mathrm{~s}, 5 \mathrm{~s}$, or $10 \mathrm{~s}$ depending on 
participant condition. 'Correct' or 'Incorrect' then appeared on the screen immediately after a response was given and the next trial commenced. Thus, one of the compounds in each task (e.g., AB and EF) was always reinforced in the presence of the other compound (e.g., $\mathrm{CD}$ and $\mathrm{GH})$. The position of the cards was systematically randomised so that the correct card appeared on the left approximately $50 \%$ of the time, and on the right approximately $50 \%$ of the time.

If participants did not respond within $1.5 \mathrm{~s}$, the next trial commenced. Trials from each discrimination task ( $\mathrm{AB}$ vs $\mathrm{CD}$ and $\mathrm{EF}$ vs $\mathrm{GH})$ were randomly intermixed. Training continued until the participant selected the correct compound consecutively ten times for each compound (e.g., AB was selected ten consecutive times and EF was also selected ten consecutive times). Once ten correct (consecutive) trials had been completed for one compound (e.g., $\mathrm{AB}$ vs $\mathrm{CD}$ ), trials for this discrimination task ceased and only the trials for the remaining task (e.g., EF vs GH) continued until ten consecutive correct responses for this task were also given.

Test Phase. After completing the training phase, the test phase instructions appeared on the screen. Participants were instructed 'Please select one of the two pictures presented. The computer will not tell you whether you are correct or incorrect. If you have been instructed to count then you should now continue counting, and press 'Next' to begin.' Those in the group receiving a cognitive load then continued counting backwards in sevens. All participants were then presented with one stimulus from the previously reinforced compound (e.g., A or B, E or F) paired with a stimulus from the previously punished compound (e.g., C or D, G or H). Each combination (A vs C, A vs D, B vs C, B vs D, E vs G, E vs H, F vs G, F vs H) was presented 5 times, and thus 40 trials in total. Participants were required to select one of the cards using the mouse cursor. They were provided with no feedback and each trial appeared on the screen immediately after a response had been given. 


\section{Results and Discussion}

A rejection criterion of $p<0.05$ was used for all analyses, Effect sizes are reported as partial eta-squared $\left(\eta^{2}\right) ; \eta_{p}^{2}=.02$ is a small effect, $\eta_{p}^{2}=.13$ is a medium effect, and $\eta_{p}^{2}=.26$ is a large effect (Cohen, 1988, 1992).

\section{Trials to Criterion During Training}

For participants receiving a cognitive load; those in the 2 s duration group took a mean $14.75( \pm 3.37)$ trials during training to reach the criterion for choosing $\mathrm{AB}$ or $\mathrm{EF}$, those in the 5s duration group took $17.43( \pm 3.52)$ trials, and those in the 10 s duration group took 12.29 $( \pm 2.85)$ trials. For participants not receiving a cognitive load; those in the $2 \mathrm{~s}$ duration group took $11.82( \pm 1.48)$ trials, those in the 5 s duration group took $11.54( \pm 1.32)$ trials and those in the 10 s duration group on average, took $11.04( \pm 1.67)$ trials to reach the criterion.

A two-way 2 (load: load vs. no load) $\times 3$ (stimulus duration: $2 \mathrm{~s}, 5 \mathrm{~s}, 10 \mathrm{~s}$ ) ANOVA revealed main effects of cognitive load, $F(1,78)=36.78, p<.001, \eta^{2}{ }_{p}=.32[95 \% \mathrm{CI}=.158$ $-.458]$ and stimulus duration, $F(2,78)=8.72, p<.001, \eta_{p}^{2}=.18[.043-.317]$, as well as a load $\times$ duration interaction, $F(2,78)=6.01, p=.004, \eta^{2}{ }_{p}=.13[.017-.263]$ demonstrating that the effect of cognitive load on the number of trials it took to reach criterion was different depending on the duration in which the stimulus remained on the screen. Simple effect analyses indicated that participants receiving cognitive load when the stimulus duration was 2 s took longer than those without a cognitive load to reach training criterion, $F(1,78)=9.33$, $p=.003$. This was also the case when the stimulus duration was $5 \operatorname{secs}, F(1,78)=37.77, p$ $<.001$. However, there was no significant effect of cognitive load on trials to criterion when the stimulus duration was $10 \mathrm{~s}, F(1,78)=1.70, p=.20$. 


\section{Most vs Least Selected Elements During Test (Over-selectivity)}

Figure 2 about here

The mean percentage of times that the most selected and least selected stimuli were chosen from reinforced compound $\mathrm{AB}$ and reinforced compound $\mathrm{EF}$ during the test was calculated providing a most-selected (e.g., A) and least-selected stimulus (e.g., B) from AB, as well as a most-selected (e.g., E) and least-selected stimulus (e.g., F) from EF. The mean most selected (e.g., A and E) and least selected (e.g., B and F) was then calculated. The mean of the most and least selected elements from the two compounds are displayed in Figure 2. These data demonstrate greater evidence of stimulus over-selectivity following $2 \mathrm{~s}$ and $5 \mathrm{~s}$ durations when participants received a cognitive load compared to receiving no cognitive load. The figure shows little evidence of over-selectivity in the $10 \mathrm{sec}$ duration group regardless of whether participants received a cognitive load.

A three-way 2 (stimulus type: most vs least) $\times 2$ (load: load vs no load) $\times 3$ (stimulus duration: $2 \mathrm{~s}, 5 \mathrm{~s}, 10 \mathrm{~s}$ ) mixed-model ANOVA was conducted on these data, demonstrating main effects of stimulus type, $F(1,78)=121.99, p<.001, \eta^{2}=.61[.469-.699]$, load, $F(1,78)=31.97, p<.001, \eta_{p}^{2}=.29[.132-.431]$, and stimulus duration, $F(2,78)=13.77, p$ $<.001, \eta_{p}^{2}=.26[.099-.396]$. Additionally, there was a stimulus type $\times$ load interaction, $F(1,78)=56.98, p<.001, \eta_{p}^{2}=.42[.256-.547]$, and stimulus type $\times$ stimulus duration interaction, $F(2,78)=12.91, p<.001, \eta^{2} p=.25[.089-.383]$. Crucially, there was also a stimulus type $\times$ load $\times$ stimulus duration interaction, $F(2,78)=12.15, p<.001, \eta^{2} p=.24$ [.081 - .373], indicating that the effect of cognitive load on stimulus over-selectivity was different depending on stimulus duration. 
To follow-up the three-way interaction, a 2 (load: load vs no load) $\times 2$ (stimulus type: most vs least) mixed-model ANOVA was conducted for each stimulus duration, as recommended by Howell (1997), with load as the between-subjects variable and stimulus type as the within-subjects variable, and percentage of times the stimuli were selected as the dependent measure. For the 2 s duration, results indicated main effects of stimulus type, $F(1,26)=30.23, p<.001, \eta^{2}{ }_{p}=.54[.243-.692]$, and load, $F(1,26)=18.06, p<.001, \eta^{2} p$ $=.41[.119-.601]$, and a stimulus $\times$ load interaction, $F(1,26)=16.80, p<.001, \eta^{2}{ }_{p}=.39$ [.106 - .588]. Simple effect analyses conducted on the stimulus type (most vs least) for the group receiving a cognitive load revealed a difference between the most and least chosen stimulus, $F(1,26)=46.05, p<.01$; however there was no significant simple effect of stimulus for the group receiving no load, $F<1$. For the $5 \mathrm{~s}$ duration, results also indicated a main effect of stimulus type, $F(1,26)=104.77, p<.001, \eta^{2}{ }_{p}=.80[.624-.868]$, and load, $F(1,26)=$ $16.61, p<.001, \eta_{p}^{2}=.39[.103-.586]$, and a stimulus $\times$ load interaction, $F(1,26)=60.71, p$ $<.001, \eta^{2}{ }_{p}=.70[.460-.802]$. Simple effect analyses conducted on the stimulus type (most vs least) for the group receiving a cognitive load revealed a difference between the most and least chosen stimulus, $F(1,26)=162.49, p<.001$, however there was no significant simple effect of stimulus for the group receiving no load, $F(1,26)=2.99, p=.096$. Finally, for the 10 s duration, results indicated a main effect of stimulus type, $F(1,26)=18.69, p<.001, \eta^{2} p$ $=.42[.126-.607]$, but no significant main effect of load, $F<1$, or stimulus $\times$ load interaction, $F<1$. Therefore, when the stimulus duration was 10 s, there was no difference in participant's selection of stimuli whether they received a cognitive load or not.

These findings replicate previous research demonstrating that stimulus overselectivity only occurs in typically-developing adults when the participant is undergoing a cognitively demanding task (e.g., Reed, 2006; Reed \& Gibson, 2005; Reynolds \& Reed, 2011a, 2011b, 2012; Reynolds, Watts, \& Reed, 2012). The results also demonstrate that the 
Running Head: STIMULUS OVER-SELECTIVITY AND CS DURATION

inclusion of a cognitively demanding task elicits stimulus over-selectivity, but this overselectivity is only significant at short stimulus durations ( $2 \mathrm{~s}$ and $5 \mathrm{~s})$. When the stimuli are presented for $10 \mathrm{~s}$, even when undergoing a cognitively demanding task, participants do not demonstrate significant over-selectivity. Theoretically, this implies that less over-selectivity is observed following longer durations because the strength of the within-compound association between the cues is higher due to the increase in co-occurrence of the elements of the compound. Additionally, results supported those within an overshadowing context (e.g., Sissons et al., 2009; Urushihara et al., 2004; Urushihara \& Miller, 2007; Westbrook et al., 1983) by showing that over-selectivity only significantly occurred at shorter stimulus durations (2s and $5 \mathrm{~s})$ but was not significantly different when undergoing a cognitively demanding task following longer durations (10s). It is worth noting that stimulus duration did not have a 'linear' effect as is observed in animal studies. Additionally, whilst overselectivity was reduced with long stimuli duration, it was not abolished as is the case for overshadowing in animal studies. These inconsistences are likely due to procedural differences.

\section{Experiment 2}

Although most theoretical perspectives of overshadowing and over-selectivity can account for the findings of Experiment 1 (e.g., Mackintosh, 1975; Miller \& Matzel, 1988; Pearce \& Hall, 1980; Stout \& Miller, 2007), they diverge in their expectations of what occurs if the overshadowing or over-selected stimulus is extinguished or revalued post-training. Within the overshadowing literature, three possibilities emerge. Firstly, empirical research has demonstrated that retrospective revaluation may occur (e.g., Dickinson \& Burke, 1996; Kaufman \& Bolles, 1981; Matzel et al., 1985; Matzel et al., 1987; Van Hamme \& 
Wasserman, 1994). That is, extinguishing or revaluing the overshadowing stimulus allows the overshadowed stimulus to exert increased behavioural control, supporting Miller and Matzel's (1988) comparator perspective, and Stout and Miller's (2007) sometimes competing retrieval (SOCR) theory. Alternatively, extinguishing or revaluing the overshadowed stimulus may reduce behavioural control (mediated extinction; Holland, 1990; Schachtman, Kasprow, Meyer, Bourne, \& Hart, 1992; Shevill \& Hall, 2004). Finally, empirical research has demonstrated no change in behavioural control following post-training extinction (e.g., Holland, 1999; Revusky, Parker, \& Coombes, 1977; supporting theoretical perspectives such as Mackintosh, 1975; Pearce \& Hall, 1980).

Within-compound associations have also been argued to play a role in determining the outcome of post-training extinction. Such within-compound association between the stimuli in a compound develop as a result of the stimuli being paired together with the outcome during initial training. Subsequent presentation of one of these stimuli will activate a memory or representation of the stimulus with which it was previously paired in compound. Such within-compound associations subsequently mediate post-training cue-interaction processes (see Luque, Flores, \& Vadillo, 2015; Wasserman \& Berglan, 1998). Thus, particularly strong within compound associations may attenuate cue competition and resultantly weaken retrospective revaluation (e.g., Wheeler \& Miller, 2008) or mediated extinction (e.g., Holland, 1990). Such research along with studies using groups known to have difficulty with forming within-compound associations such as those with ASD (Reed, 2011) suggest that consideration of the role of within-compound associations is fundamental in explaining over-selectivity effects.

Research using rats in a conditioned flavour aversion paradigm has demonstrated that short duration CSs result in weak odours being overshadowed by salient tastes but potentiate odours with long CS durations and that post-training extinction of the salient taste following 
long CS durations results in mediated extinction (Westbrook, Homewood, Horn, \& Clarke, 1983). Crucially, following simultaneous, rather than serial, CS presentation, post-training extinction following an overshadowing preparation has been shown to result in mediated extinction (Schachtman, Kasprow, Meyer, Bourne, \& Hart, 1992; Shevill \& Hall, 2004), whereas retrospective revaluation has been demonstrated following serial presentations (e.g., Matzel, Schachtman, \& Miller, 1985; Matzel, Schuster, \& Miller, 1987). Arguably, this may be because simultaneous presentations result in stronger within-compound associations as a result of superior contiguity (Rescorla \& Wagner, 1972). Sissons et al. (2009) also demonstrated that following shorter CS durations, post-training extinction resulted in retrospective revaluation whereas mediated extinction occurred following extinction of CSs with longer durations. Therefore, strong within-compound associations attenuate cue competition thus resulting in mediated extinction following post-training extinction, whereas moderate within-compound associations enhances cue competition and results in retrospective revaluation following post-training extinction (but see Holland, 1999).

Theoretically, from a comparator perspective, with short durations, cue competition will occur post-training, thus extinction of the overshadowing stimulus (the comparator stimulus) will result in retrospective revaluation. On the other hand, with longer stimulus durations (when cue competition does not occur), post-training extinction will result in mediated extinction. Fundamentally, retrospective revaluation depends on the formation of a within-compound association between the stimuli. Therefore, the current study aimed to explore the effect of stimulus duration on stimulus control following a revaluation procedure in an over-selectivity paradigm. As with Sissons et al. (2009), the intermediate duration time ( $5 \mathrm{~s}$ in this case) was omitted in order to focus on the extremes ( $2 \mathrm{~s}$ and $10 \mathrm{~s})$. Participants were therefore randomly assigned to one of two groups, $2 \mathrm{~s}$ or $10 \mathrm{~s}$. As with the experimental groups in Experiment 1, all participants received a cognitively demanding task; they were 
required to vocally count backwards in sevens from a random five-digit number throughout the entire experiment. From a comparator hypothesis, it was hypothesised that the posttraining revaluation procedure following the $2 \mathrm{~s}$ duration would result in retrospective revaluation whereas following the 10s duration, mediated extinction would be demonstrated.

\section{Method}

\section{Participants and Materials}

Forty students participated in the study, 15 males and 25 females, with an age range of 18 to 20 years $(M=18.88$ years, $S D=0.79)$. Participants were randomly assigned to either the $2 \mathrm{~s}(\mathrm{~N}=20)$ or 10 s group $(\mathrm{N}=20)$.

The materials were identical to Experiment 1 with the exception that additional abstract stimuli taken from Wingdings, Wingdings 2 and Symbol fonts in Microsoft Word 2010 were used during the revaluation phase.

\section{Procedure}

As with Experiment 1, participants first completed the AQ by hand. No participants scored above the cut-off point $(>32)$ therefore no participants were excluded. Table 1 depicts the automated procedure used.

Training Phase. The training phase was identical to Experiment 1.

Test Phase. The test phase was identical to Experiment 1.

Revaluation Phase. Based on the responses during the test phase, the over-selected stimulus from both the $\mathrm{AB}$ and $\mathrm{EF}$ compounds was then identified. The over-selected stimulus from each compound was then re-valued (e.g., A or B, and E or F), whereby the over-selected stimulus was presented simultaneously with a previously unseen, and therefore novel, stimulus. Participants received 'Correct' feedback for selecting the novel stimulus and 
'Incorrect' feedback for selecting the previously over-selected stimulus. Participants continued to the final phase following the selection of the novel stimulus on ten consecutive trials.

Re-testing Phase. The re-testing phase was identical to the test phase, comprising of 40 trials in total.

\section{Results and Discussion}

\section{Trials to Criterion During Training}

Participants in Group 2s took a mean of $17.18( \pm 5.66)$ trials to reach criterion for choosing the reinforced compound stimulus in both discrimination tasks ( $\mathrm{AB}$ or $\mathrm{EF}$ ), and participants in Group 10s took a mean of $13.65( \pm 2.81)$ trials to reach criterion. A t-test revealed a difference between the two groups on the number of trials taken to reach criterion $t(38)=2.49, p=.02, d=0.78$, demonstrating that it took participants longer to learn the discrimination when the stimulus duration was only 2 s compared to when the stimulus duration was 10 s.

\section{Most vs Least Selected Elements (Over-selectivity) During Test and Re-Test}

Figure 3 about here

Figure 3 displays the percentage of times the most selected and least selected stimulus from the initially reinforced compound was chosen in the initial test phase (pre-revaluation), and the re-testing phase following revaluation training (post-revaluation). Pre-revaluation, these data indicate greater over-selectivity after the $2 \mathrm{~s}$ compared to the $10 \mathrm{~s}$ stimulus duration. A two-way mixed model ANOVA 2 (stimulus: most vs least) $\times 2$ (group: 2 s, 10 s) indicated a 
main effect of stimulus, $F(1,38)=207.06, p<.001, \eta^{2}=.85[.737-.892]$, and group, $F(1,38)=57.60, p<.001, \eta^{2}=.60[.381-.721]$, and a stimulus $\times$ group interaction, $F(1,38)$ $=82.60, p<.001, \eta^{2}{ }^{2}=.69[.493-.779]$. Simple effect analyses conducted on the stimulus type (most vs least) revealed a difference in the 2 s group, $F(1,38)=275.61, p<.001$, and in the 10s group, $F(1,38)=14.05, p=.001$.

Post-revaluation, Figure 3 demonstrates that in the 2 s group, behavioural control exerted by the previously most-selected stimulus was reduced, whereas control exerted by the least selected stimulus increased. In the 10 s group, behavioural control by both stimuli decreased post-revaluation. A three-way mixed model ANOVA 2 (stimulus: most vs least) $\times$ 2 (phase: pre- vs post-revaluation) $\times 2$ (group: 2 s, 10 s) showed main effects of stimulus type, $F(1,38)=25.76, p<.001, \eta^{2}{ }_{p}=.40[.196-.600]$, phase, $F(1,38)=26.73, p<.001, \eta^{2}{ }_{p}=.41$ $[.171-.579]$, and group, $F(1,38)=15.63, p<.001, \eta^{2}{ }_{p}=.29[.074-.481]$. The stimulus $\times$ group interaction, $F(1,38)=6.36, p=.02, \eta^{2}{ }^{2}=.14[.004-.341]$, phase $\times$ group interaction, $F(1,38)=31.11, p<.001, \eta^{2} p=.47[.206-.608]$, stimulus $\times$ phase interaction, $F(1,38)=$ $22.99, p<.001, \eta_{p}^{2}=.38[.138-.551]$ were all significant. Crucially, there was also a three way interaction, $F(1,38)=13.70, p=.001, \eta^{2}{ }_{p}=.27[.057-.458]$.

As a result of the three-way interaction, two separate two-factor ANOVAs (stimulus type $\times$ phase) were conducted on the 2 s group and the 10 s group. The ANOVA conducted on the 2 s group revealed no statistically significant main effect of phase, $F<1$, but a main effect of stimulus, $F(1,19)=35.20, p<.001, \eta^{2}{ }_{p}=.65[.325-.779]$, and a stimulus $\times$ phase interaction, $F(1,19)=47.46, p<.001, \eta^{2}{ }^{2}=.71[.423-.820]$. Simple effect analyses conducted on the stimulus type (most vs least) pre-revaluation revealed a difference, $F(1,19)$ $=82.95, p<.001$, indicating initial over-selectivity, but no statistically significant simple effect of stimulus post- revaluation, $F<1$, demonstrating that over-selectivity was no longer present following revaluation training. Simple effect analyses conducted on the phases (pre- 
revaluation and post- revaluation) for the most-selected stimulus revealed a reduction in choice from pre- to post- revaluation, $F(1,19)=19.87, p<.001$, indicating the effect of extinction on that stimulus. However, there was an increase in choice for the least selected stimulus in the post- compared to pre-revaluation, $F(1,19)=27.46, p<.001$, indicating an increase in choice. The ANOVA conducted on the 10s group revealed a main effect of phase, $F(1,19)=49.54, p<.001, \eta_{\mathrm{p}}^{2}=.72[.437-.825]$, but no significant main effect of stimulus type, $F(1,19)=2.76, p=.11, \eta_{p}^{2}=.13[.000-.391]$, or stimulus $\times$ phase interaction, $F<1$.

Figure 4 about here

Figure 4 displays the mean percentage change scores from the initial test phase (prerevaluation) to the re-testing phase following revaluation training (post- revaluation) for the most selected and least selected stimulus from the initially reinforced compound (postrevaluation minus pre- revaluation) in each stimulus duration group (2s, 10s). A two-way mixed model ANOVA 2(stimulus: most vs least) $\times 2$ (group: $2 \mathrm{~s}, 10 \mathrm{~s})$ carried out on the change scores showed a significant main effect of stimulus, $F(1,38)=26.59, p<.001, \eta^{2} \mathrm{p}=$ $.41[.169-.578]$, group, $F(1,38)=31.08, p<.001, \eta_{p}^{2}=.45[.206-.608]$, and a significant stimulus $\times$ group interaction, $F(1,38)=12.35, p=.001, \eta_{p}^{2}=.25[.046-.440]$. Simple effect analyses conducted on the stimulus (most vs least) in the two groups revealed a statistically significant difference in the 2 s group, $F(1,38)=37.60, p<.001$, but no significant difference in the 10 s group, $F(1,38)=1.35, p=.25$. Simple effect analyses conducted on the groups revealed a statistically significant difference for the under-selected stimulus, $F(1,38)=47.26$, $p<.001$, but no statistically significant difference for the over-selected stimulus, $F(1,38)=$ $3.63, p<.05$. 
These results replicate the findings of Experiment 1, demonstrating undergoing a cognitive demanding task elicited greater over-selectivity following the 2 s duration compared to the 10s duration. Additionally, results demonstrated a revaluation effect in the shorter stimulus duration time only. That is, following shorter stimulus duration, revaluation of the previously over-selected stimulus results in reduced behavioural control by this stimulus and allows the previously under-selected stimulus to gain behavioural control. However, following longer-stimulus duration, no such revaluation effect was found; behavioural control by both the over-selected and under-selected stimulus was reduced (mediated extinction). These results are, therefore, in line with those from the overshadowing literature (e.g., Sissons et al., 2009).

These data from the revaluation phase also help to disambiguate the interpretation of the findings of over-selectivity from Experiment 1, and the first phase of the current study. A simple and intuitive explanation for over-selectivity is that some participants have difficulty paying attention to both A and B. As a result, they might only learn (or learn more) about one of them, producing the over-selectivity effect. The results of Experiment 1 are perfectly consistent with this explanation, which could take a purely attentional (i.e., participants do not observe the element), or a perceptual masking (i.e., participants cannot 'see' the element), form: over-selectivity is stronger when participants have few cognitive resources (i.e., cognitive load) and the stimuli are presented briefly. As the opportunities to pay due attention to both stimuli increase (either because of the lack of cognitive load or because of the increased exposure to stimuli), the effect disappears. That, in the $2 \mathrm{~s}$ duration condition, extinction of the previously over-selected stimulus results in increased behavioural control being exerted by the previously under-selected stimulus, suggests that this cannot be a full explanation of the results (see also Leader et al., 2009). If participants had not paid attention to the previously under-selected element, then manipulation of the previously over-selected 
element would not have any impact on the degree to which the previously under-selected element controls behaviour: if it has not been learned about in the first phase, then it should not come to control behaviour any more in the second phase as a result of changes to the value of the previously over-selected, and now extinguished, element.

\section{Experiment 3}

The results from the first two experiments suggest the need to consider the role of within-compound associations in explaining over-selectivity. Previous work has argued that, as the strength of the within-compound association increases, the degree of cue competition (i.e., overshadowing or over-selectivity) will decrease (e.g., Dickinson \& Burke, 1996; Sissons et al., 2009). Longer stimulus durations in the two preceding experiments reported here may have served to increase the strength of the within-compound association by increasing the co-occurrence of the elements of the compound. Stronger within-compound associations, thus, weaken cue competition, and decrease over-selectivity. Furthermore, revaluation training in Experiment 2 only resulted in retrospective revaluation following shorter durations when the within-compound associations would have been weaker (see also Wheeler \& Miller, 2008). Following longer durations, and, therefore, stronger withincompound associations, revaluation training resulted in mediated extinction.

In order to directly explore the role of within-compound associations in overselectivity, Experiment 3 directly manipulated the consistency with which the A and B (and E and F) elements of the compound stimulus were paired during initial training. To the degree that these stimuli are paired, within-compound associations would be stronger, and this provides an additional manipulation to test the contribution of within-compound associations to the over-selectivity effect (see Dickinson \& Burke, 1996). 
To this end, participants were randomly assigned to one of three groups: Consistent$\mathrm{R} 1$, Consistent-R2, or Varied. The procedure remained largely the same as in Experiment 2; however, the consistency with which the elements of the compounds were paired during initial training was varied according to group. The Varied group were presented with the compounds in all possible elemental variants of $\mathrm{AB}+, \mathrm{CD}-; \mathrm{EF}+, \mathrm{GH}-$. This served to reduce $\mathrm{AB}$ and EF consistency, while still maintaining attention to the compounds. The Consistent groups were presented with 18 trials of each task ( $\mathrm{AB}+\mathrm{CD}-$; and $\mathrm{EF}+\mathrm{GH}-)-36$ trials in total. Thus, all groups received 36 trails, regardless of whether they gave the correct response.

Participants in the Consistent-R2 and Varied groups then received revaluation training with the over-selected stimulus from both compounds (e.g., A or B, and E or F) by presenting the over-selected stimulus with a novel stimulus and reinforcing selection of the novel stimulus (see Experiment 2). The finding from Experiment 2, that responding to the previously underselected stimulus increased following revaluation, was interpreted as being a result of its revaluation. However, an alternative explanation is that participants had forgotten its value. This seems unlikely, as simple effect analyses conducted on the phases (pre- revaluation and post- revaluation) for the most-selected stimulus showed a difference pre- and post- revaluation, $F(1,19)=34.77, p<.001$, and there was also a simple effect of phase for the least-selected stimulus, $F(1,19)=24.97, p<.001$. Although this analysis was not included in the results of Experiment 2 (given that the interaction was nonsignificant), the analysis does demonstrate a reduction in responding from pre to post in the underselected stimulus for the longer duration, which is contrary to the increase in responding pre to post in the underselected stimulus for the short duration. Therefore, while the findings of Experiment 2 discredit the trace decay perspective, Experiment 3 aimed to provide further 
evidence in support of the role of within-compound associations by only revaluing one of the compounds in the Consistent-R1 group (i.e., revaluing AB, but not EF).

\section{Method}

\section{Participants and Materials}

Sixty-six students participated in the study, 21 males and 45 females, with an age range of 18 to 22 years $(M=19.20$ years, $S D=1.08)$. Participants were randomly assigned to either the Consistent-R1 group $(\mathrm{N}=22)$, Consistent-R2 group $(\mathrm{N}=22)$ or Varied group $(\mathrm{N}$ $=22)$.

The materials were identical to Experiment 2. No participants scored above the cutoff point $(>32)$ on the AQ; therefore, no participants were excluded, and all participants were required to vocally count backwards in sevens from a five-digit number during the procedure.

\section{Procedure}

Table 1 depicts the automated procedure used.

Training Phase. The training phase instructions were identical to those given in Experiments 1 and 2, and participants were presented with two simultaneous discrimination tasks (AB vs $\mathrm{CD}$, and EF vs $\mathrm{GH})$. Groups Consistent-R1 and Consistent-R2 were presented with 18 trials of each task (therefore 36 trials in total), regardless of whether they gave the correct response. Group Varied received the same initial instructions, and completed the same discrimination task, but the compounds presented included all possible variants of $\mathrm{AB}+$, CD-; EF+, GH- (i.e., AB+CD-, AE+ CD-, AF+ CD-, AB+ GH-, AE+ GH-, AF+ GH-, AB+ CG-, AE+ CG-, AF+ CG-, AB+CH-, AE+ CH-, AF+ CH-, AB+ DG-, AE+, DG-, AF+, DG-, $\mathrm{AB}+\mathrm{DH}-, \mathrm{AE}+\mathrm{DH}-, \mathrm{AF}+\mathrm{DH}-, \mathrm{BE}+\mathrm{CD}-, \mathrm{BF}+\mathrm{CD}-, \mathrm{BE}+\mathrm{GH}-, \mathrm{BF}+\mathrm{GH}-, \mathrm{BE}+\mathrm{CG}-, \mathrm{BF}+$ CG-, BE+ CH-, BF+ CH-, BE+ DG-, BF+ DG-, BE+ DH-, BF+ DH-, EF+ CD-, EF+ GH-, $\mathrm{EF}+\mathrm{CG}-, \mathrm{EF}+\mathrm{CH}-, \mathrm{EF}+\mathrm{DG}-\mathrm{EF}+\mathrm{DH}-)$. This meant that individual elements had less 
chance to form within-compound associations with one another - for this group, each variant was shown once (therefore 36 trials in total). The compounds remained on the screen for $2 \mathrm{~s}$ before "Respond Now" appeared at the bottom of the screen.

Test Phase. The test phase was identical to the test phase in Experiments 1 and 2.

Revaluation Phase. The revaluation phase for groups Consistent-Reval2 and Varied was identical to the revaluation phase in Experiment 2 with the over-selected stimulus from each compound (e.g., A or B, and E or F) being revalued by presenting the over-selected stimulus with a novel stimulus and reinforcing selection of the novel stimulus. Participants in the Consistent-R1 group only received revaluation of the over-selected stimulus from one compound (e.g., A or B) and not the second compound (e.g., E or F). All participants continued to the final phase following the selection of the novel stimulus on ten consecutive trials.

Re-testing Phase. The re-testing phase was identical to the test phase.

\section{Results and Discussion}

\section{Most vs Least Selected Elements (Over-selectivity) During Test and Re-Test}

Figure 5 about here

The percentage choice for the most-selected and least-selected stimuli from the initially reinforced compound chosen in the initial test phase (pre-revaluation), and the retesting phase post-revaluation are depicted in Figure 5. There was pre-revaluation overselectivity demonstrated in all three groups. A two-way mixed-model ANOVA 2 (stimulus: most vs least) $\times 3$ (group: Consistent-R1, Consistent-R2, Varied) indicated a main effect of stimulus, $F(1,63)=149.41, p<.001, \eta_{p}^{2}=.70[.57-.78]$ demonstrating over-selectivity. 
However, the main effect of group, $F(1,63)=1.19, p=.31, \eta^{2}{ }_{p}=.04[.00-.13]$, and the stimulus $\times$ group interaction, $F(2,63)=3.03, p=.06, \eta^{2}=.09[.00-.22]$ were not significant. Therefore, there were no significant differences in over-selectivity between the three groups.

During revaluation training, the Consistent-R2 and Varied groups both received revaluation training for the most-selected stimulus from both simultaneous discrimination tasks (compounds $\mathrm{AB}$ and $\mathrm{EF}$ ). Therefore, post-revaluation, Figure 5 shows the mean percentage of times the most-selected and least-selected stimulus was selected. However, the Consistent-R1 group received revaluation training for the most-selected stimulus from only one simultaneous discrimination task $(\mathrm{AB})$, and Figure 5 depicts the percentage of times the most-selected and least-selected stimulus was selected from this compound only (and not the compound from the task that did not receive revaluation, i.e., EF). The figure demonstrates reduced control over behaviour by the previously most-selected stimulus, and increased control by the previously least-selected stimulus in both Consistent groups. However, in the Varied group, while there is a slight decrease in behavioural control exerted by the mostselected stimulus, there is very little change in responding overall.

A three-way mixed-model ANOVA 2 (stimulus: most vs least) $\times 2$ (phase: pre- vs post-revaluation) $\times 3$ (group: Consistent-R1, Consistent-R2, Varied) indicated a main effect of stimulus type, $F(1,63)=66.26, p<.001, \eta^{2}{ }_{p}=.51[.33-.63]$, but no significant main effect of phase, $F<1$, or group, $F(1,63)=1.99, p=.15, \eta^{2}{ }^{2}=.06[.00-.15]$. The stimulus $\times$ group interaction, $F(2,63)=2.71, p=.08, \eta^{2}=.08[.00-.21]$, and time $\times$ group interaction, $F<1$, were not significant. However, there was a stimulus $\times$ time interaction, $F(1,63)=42.71, p<$ $.001, \eta_{p}^{2}=.40[.22-.54]$, and, crucially, there was also a three-way interaction, $F(2,63)=$ 4.99, $p=.01, \eta^{2} p=.14[.01-.28]$. 
To follow up the three-way interaction, three separate two-factor ANOVAs (stimulus type $\times$ phase) were conducted on the Consistent-R1 group, Consistent-R2 group, and the Varied group. The ANOVA conducted on the Consistent-R1 group demonstrated no statistically significant main effect of phase, $F<1$, but a main effect of stimulus, $F(1,21)=$ $8.51, p=.01, \eta_{p}^{2}=.29[.02-.52]$, and a stimulus $\times$ phase interaction, $F(1,21)=18.41, p<$ $.001, \eta^{2}{ }_{p}=.47[.14-.65]$. Simple effect analyses conducted on the stimulus type (most vs least) pre-revaluation demonstrated a difference, $F(1,21)=25.12, p<.001$, showing initial over-selectivity. However, post-revaluation, there was no statistically significant simple effect of stimulus type, $F(1,21)=1.11, p>.05$ demonstrating that over-selectivity was no longer present following revaluation training. Simple effect analyses conducted on the phases (pre- revaluation and post- revaluation) demonstrated a reduction in choice for the most selected stimulus from pre- to post- revaluation, $F(1,21)=8.73, p<.001$, and an increase in choice for the least selected stimulus from pre- to post- revaluation, $F(1,21)=$ $9.69, p<.001$.

The ANOVA conducted on the Consistent-R2 group demonstrated no statistically significant main effect of phase, $F<1$, but a main effect of stimulus, $F(1,21)=34.71, p<$ $.001, \eta^{2}{ }_{p}=.62[.31-.76]$, and a stimulus $\times$ phase interaction, $F(1,21)=82.34, p<.001, \eta^{2}{ }^{2}=$ $.80[.58-.87]$. Simple effect analyses conducted on the stimulus type (most vs least) prerevaluation revealed a difference, $F(1,21)=185.24, p<.001$, but no statistically significant simple effect of stimulus post- revaluation, $F<1$. Therefore, like for the Consistent-R1 group, there was evidence of initial over-selectivity however over-selectivity was no longer present following revaluation training. Simple effect analyses conducted on the phases for the most-selected stimulus revealed a reduction in choice from pre- to post- revaluation, $F(1,21)=28.59, p<.001$ and an increase in choice for the least selected stimulus from postto pre-revaluation, $F(1,21)=56.03, p<.001$. Therefore, again, results were comparable to 
Running Head: STIMULUS OVER-SELECTIVITY AND CS DURATION

the Consistent-R1 group in that following revaluation, behavioural control exerted by the most selected stimulus was reduced and responding to the least selected stimulus increased.

The ANOVA conducted on the Varied group revealed a main effect of stimulus, $F(1,21)=27.81, p<.001, \eta_{\mathrm{p}}^{2}=.57[.24-.72]$, but no significant main effect of phase, $F<1$, or stimulus $\times$ phase interaction, $\mathrm{F}(1,21)=1.04, p=.32, \eta^{2} p=.05[.00-.28]$.

Figure 6 about here

Figure 6 shows the mean percentage change scores from the initial test phase (prerevaluation) to the re-testing phase post-revaluation for the most selected and least selected stimulus from the initially reinforced compound (post- revaluation minus pre- revaluation) in each group (Consistent-R1, Consistent-R2, Varied). A two-way mixed model ANOVA 2(stimulus: most vs least) $\times 3$ (group: Consistent-R1, Consistent-R2, Varied) carried out on the change scores showed no significant main effect of group, $F<1$ but a main effect of stimulus, $F(1,63)=42.71, p<.001, \eta^{2}{ }_{p}=.40[.22-.54]$, and a stimulus $\times$ group interaction, $F(2,63)=4.99, p=.01, \eta^{2}{ }_{p}=.14[.01-.28]$. Simple effect analyses conducted on the stimulus (most vs least) in the three groups revealed a difference in the Consistent-R1 group, $F(1,20)=22.08, p<.001$, and the Consistent-R2 group, $F(1,20)=14.15, p<.001$, but no significant difference in the Varied group, $F(1,20)=1.50, p>.05$.

Taken together, the results replicate the over-selectivity findings of Experiments 1 and 2. Furthermore, when the elements of the compounds were consistently paired during initial training, revaluation of the over-selected stimulus reduced behavioural control exerted by this stimulus and increased behavioural control exerted by the previously under-selected stimulus. However, when the consistency of the elements of the compounds was reduced during initial training, there was no demonstration of a revaluation effect. 


\section{Most vs Least Selected Elements (Over-selectivity) of the Revalued Compound vs the Non- Revalued Compound in Group Consistent-R1 During Test and Re-Test}

In order to establish whether the post-revaluation finding that behavioural control exerted by the most selected stimulus decreases and control by the least selected stimulus increases, is a genuine revaluation effect, the most selected stimulus from the compound from only one simultaneous discrimination task $(\mathrm{AB})$ was revalued (and not from the second discrimination task, EF) in group Consistent-R1.

Figure 7 about here

Figure 7 displays the percentage of times the most selected and least selected stimulus was chosen from the initially reinforced $\mathrm{AB}$ compound and $\mathrm{EF}$ compound, in the initial test phase (pre-revaluation), and the re-testing phase post-revaluation (whereby the most selected stimulus from $\mathrm{AB}$ was revalued but the most selected stimulus from EF was not revalued). The data demonstrate that, following revaluation training for the previously reinforced $\mathrm{AB}$ compound, behavioural control from the most selected stimulus was reduced, and the previously least-selected stimulus exerted greater behavioural control. However, for the EF compound, where no revaluation training was given, there was very little change in responding from pre to post test for both the most- and least-selected stimulus.

A three-way repeated measures ANOVA 2 (stimulus: most vs least) $\times 2$ (phase: prevs post-revaluation $) \times 2$ (task compound: $\mathrm{AB}$ vs $\mathrm{EF})$ indicated a main effect of stimulus type, $F(1,21)=42.97, p<.001, \eta^{2}=.67[.38-.79]$, but no significant main effects of phase or task, $F S<1$. The task $\times$ phase interaction was also non-significant, $F<1$. However, there was a task $\times$ stimulus interaction, $F(1,21)=11.74, p=.003, \eta_{p}^{2}=.36[.06-.58]$ and stimulus $\times$ 
time interaction, $F(1,21)=8.58, p=.01, \eta^{2}{ }_{p}=.29[.02-.53]$. There was also a three way interaction, $F(1,21)=7.08, p=.02, \eta_{p}^{2}=.25[.01-.50]$.

Two separate two-factor ANOVAs (stimulus type $\times$ phase) were conducted on the compound that was revalued (AB) and the compound that was not revalued (EF). The ANOVA conducted on the AB compound task demonstrated no statistically significant main effect of phase, $F<1$, but a main effect of stimulus, $F(1,21)=5.92, p=.02, \eta^{2} p=.22[.00-$ $.47]$, and a stimulus $\times$ phase interaction, $F(1,21)=15.84, p=.001, \eta^{2}=.43[.11-.63]$. Simple effect analyses conducted on the stimulus type (most vs least) pre-revaluation revealed a difference, $F(1,21)=20.85, p<.001$, but no statistically significant simple effect of stimulus post- revaluation, $F(1,21)=1.13, p>.05$. Therefore, revaluation training was effective in reducing the over-selectivity that was present at pre-revaluation. Simple effect analyses conducted on the phases (pre- revaluation and post- revaluation) for the mostselected stimulus revealed a reduction in choice from pre- to post- revaluation, $F(1,21)=$ $8.22, p<.001$, and an increase in choice for the least selected stimulus from pre- to postrevaluation, $F(1,21)=7.62, p<.01$.

The ANOVA conducted on the EF compound task demonstrated a main effect of stimulus, $F(1,21)=46.92, p<.001, \eta^{2}{ }^{2}=.69[.41-.80]$, but no significant main effect of phase or stimulus $\times$ phase interaction, $F_{S}<1$. Therefore, there was no change in overselectivity from pre- to post- test.

Figure 8 about here

The mean percentage change scores from the initial test phase to the re-testing phase post-revaluation for the most-selected and least-selected stimulus from the initially reinforced compound (post- revaluation minus pre- revaluation) for each compound (AB vs $\mathrm{EF}$ ) in the 
Consistent-R1 group, is displayed in Figure 8. A two-way 2 (stimulus: most vs least) $\times 2$ (task: AB vs EF) mixed model ANOVA showed no significant main effect of task, $F<1$, but a main effect of stimulus, $F(1,21)=8.58, p=.01, \eta^{2}=.29[.02-.53]$ and a stimulus $\times$ task interaction, $F(1,21)=7.08, p=.01, \eta_{p}^{2}=.25[.01-.50]$. Simple effect analyses conducted on the stimulus (most vs least) in the two tasks revealed a difference for the revalued compound, $\mathrm{AB}, F(1,21)=16.56, p<.001$, but no significant difference for the compound that was not revalued, EF, $F<1$.

These results provide direct support for the interpretation of the results of Experiment 2 , that the increase in responding to the previously underselected stimulus was due to its value having been revalued, and not due to trace decay given that only the underselected stimulus of the compound undergoing revaluation, and not the compound for which revaluation was not given, exerted behavioural control following revaluation.

\section{General Discussion}

Three experiments aimed to explore the effects of stimulus durations and post-training revaluation within an over-selectivity paradigm. Four main findings emerged: Firstly, results replicated previous work (e.g., Broomfield et al., 2008a, 2008b; 2010; Reed, 2006; Reed \& Gibson, 2005; Reynolds \& Reed, 2011a, 2011b, 2012; Reynolds et al., 2012), demonstrating that over-selectivity occurs in typically developing adults (screened for high functioning ASD) when undergoing a cognitively demanding task. Secondly, the cognitively demanding task elicited greater over-selectivity when stimuli were presented at short durations $(2 \mathrm{~s}$ and $5 \mathrm{~s})$ compared to a longer duration (10s). These results support the perspective that overselectivity shares important characteristics with the similar and more-commonly investigated phenomenon of overshadowing (e.g., Pavlov, 1927). Overshadowing has been found to occur at shorter stimulus durations, but not with longer durations (e.g., Sissons et al., 2009; 
Urushihara et al., 2004; Urushihara \& Miller, 2007; Westbrook et al., 1983). The current study supports these findings as, although potentiation was not observed, results did demonstrate a reduction in over-selectivity. These differences are likely to be either a species effect, or more likely a procedural effect.

The third finding to emerge was that post-training revaluation resulted in retrospective revaluation (e.g., Dickinson \& Burke, 1996; Kaufman \& Bolles, 1981; Matzel et al., 1985; Matzel et al., 1987; Miller \& Matzel, 1988; Stout \& Miller, 2007; Van Hamme \& Wasserman, 1994) for stimuli presented at shorter durations (2s; see also Broomfield et al., 2010), and mediated extinction (e.g., Holland, 1990; Schachtman et al., 1992; Shevill \& Hall, 2004) for stimuli presented at longer durations (10s). Again, this emulates the findings by Sissons et al. (2009) who demonstrated the same effects within an overshadowing paradigm. The fourth important finding was that post-training revaluation resulted in retrospective revaluation only when the stimuli were consistently paired during initial training, emulating the findings by Dickinson and Burke (1996), who used another cue competition procedure and observed similar effects.

Theoretically, all three experiments contribute to our understanding of overselectivity, particularly by exemplifying the need to consider the role of within-compound associations in explaining over-selectivity. Research has previously observed that stronger within-compound associations results in attenuation in the degree of cue competition (e.g., Dickinson \& Burke, 1996; Luque et al., 2015; Reed et al., under review; Sissons et al., 2009; Wasserman \& Berglan, 1998; Wheeler \& Miller, 2008; see Urcelay, 2017). Results from Experiments 1 and 2 are compatible with this explanation in that longer durations would have increased the strength of the within-compound association between the cues by increasing the co-occurrence of the elements of the compound and thus weakening cue competition and decreasing over-selectivity. On the other hand, shorter durations would weaken the within- 
compound association compared to the longer durations, because the longer two stimuli are simultaneously presented, the stronger the association between them will be (Rescorla, 1981) and thus increasing cue competition and enhancing the over-selectivity effect.

Additionally, the differential effects of post-training revaluation following short or long stimulus durations also demonstrate the role of within-compound associations. The stronger within-compound associations (and thus weaker cue competition) following longer durations results in mediated extinction (e.g., Holland, 1990), whereas, the weaker withincompound associations (and thus stronger cue competition) following shorter durations results in retrospective revaluation (e.g., Wheeler \& Miller, 2008).

Experiment 3 directly manipulated the within compound associations by varying the consistency with which the A and B elements of the compound stimulus were paired during initial training. When consistently pairing the $\mathrm{A}$ and $\mathrm{B}$ elements, the within-compound associations would be expected to be stronger, whereas when reducing the consistency with which A and B are paired, the within-compound associations would be expected to be weaker. The findings demonstrated that consistent pairing of A and B resulted in retrospective revaluation whereas reducing contingency resulted in no revaluation.

It is of note that previous research (e.g., Liljeholm \& Balleine, 2007) has demonstrated that both retrospective revaluation and mediated extinction are observed depending on how the stimuli are presented. Liljeholm and Balleine (2007) found that high degrees of physical similarity of elements resulted in mediated extinction whereas distinct elements resulted in retrospective revaluation. Additionally, functional similarity (acquired equivalence and distinctiveness) was found to increase mediated extinction and retrospective revaluation. This provides a potentially alternative explanation to within-compound associations of the current results, and, along with other alternative theoretical explanations, such as configural processes, should be explored in future research. Additionally, the longest 
stimulus duration used in the current studies was only 10 s whereas research with nonhuman species (e.g., Sissons et al., 2009) has implemented much longer cues. It was decided to implement a maximum of duration of 10 s in Experiment 1 due to the detrimental effect of boredom in human participants, however, future research should implement longer durations comparable to nonhuman studies. Moreover, further research could take measures of the actual degree to which the two stimuli are presented to the participants, as an indirect measure of within-compound associative strength (perhaps employing eye-tracking technology to capture joint attentional responses across the elements). It is also important to investigate alternative roles of cue duration by, for example, studying the effect of the duration of the stimulus relative to inter-trial intervals (see Urcelay, 2017; Urcelay \& Miller, 2009) on over-selectivity.

Theoretically, the results of Experiment 1 can be explained by an attention deficit perspective of over-selectivity (e.g., Dube \& McIlvane, 1999; Koegel \& Schreibman, 1977; Lovaas \& Schreibman, 1971; Lovaas et al., 1971) in that failing to attend to all elements of the compounds during initial training results in only certain elements subsequently controlling responding, giving rise to the over-selectivity effect. Indeed, in Experiment 1, when undergoing a cognitively demanding task, as well as with shorter stimulus durations, stronger over-selectivity is seen. However, as the opportunities to pay due attention to both elements of the compound increase (either because of the lack of cognitive load or because of the increased stimulus duration), the over-selectivity effect disappears. However, the findings of retrospective revaluation in Experiments 2 and 3 entirely discredit the attention deficit perspective because in order for the initially under-selected stimulus to re-emerge and control behaviour, it would have had to have been attended to in initial training (see also Broomfield et al., 2010). Alternatively, the findings can be accounted for by a variant of the comparator hypothesis (e.g., Denniston, et al., 2001; Matzel et al., 1985; Miller \& Matzel, 
1988; Miller \& Schachtman, 1985). From such a perspective, the under-selected stimulus is learnt about and attended to in initial training and revaluing the over-selected stimulus attenuates the strength of the comparator stimulus, allowing this previously under-selected stimulus to emerge to control behavior (see Reed, 2006).

It is also worth noting that the current research (see also Reynolds \& Reed, 2011a; 2011b; 2012; Reynolds et al., 2012) demonstrates an increase in over-selectivity when participants are undergoing a cognitively demanding task. However, research has demonstrated that other cue competition effects (e.g., blocking) are impaired with the addition of a cognitive load (e.g., De Houwer \& Beckers, 2002). Indeed, such findings have been taken as strong support for accounts of learning which argue that learning depends on the involvement of propositional reasoning processes, which require attentional/cognitive resources (e.g., Mitchell, De Houwer \& Lovibond, 2009). Thus, any secondary tasks that require cognitive resources would be predicted to impair learning. Furthermore, the current finding that longer stimulus duration reduces over-selectivity is also problematic for propositional accounts of learning which would predict that longer stimuli duration should allow more time for propositional reasoning processes and subsequently higher overselectivity.

In summary, the current experiments extend previous work on stimulus duration effects within the overshadowing literature, to an over-selectivity paradigm by demonstrating the occurrence of over-selectivity following shorter stimulus duration but not longer stimulus duration, whilst also showing differential effects of post-training revaluation depending on stimulus duration. Theoretically, the studies support assumptions based on an extended comparator hypothesis and highlight the importance of the role of within-compound associations in understanding the phenomenon of over-selectivity. 


\section{References}

Bailey, S. L. (1981). Stimulus over-selectivity in learning disabled children. Journal of Applied Behavior Analysis, 14, 239-248.

Baron-Cohen, S., Wheelwright, S., Skinner, R., Martin, J., \& Clubley, E. (2001). The Autism Spectrum Quotient (AQ): Evidence from the Asperger Syndrome/High Functioning Autism, Males and Females, Scientists and Mathematicians. Journal of Autism and Developmental Disorders, 31, 5-17.

Boucher, J., \& Warrington, E. K. (1976). Memory deficits in early infantile autism: some similarities to the amnesic syndrome. British Journal of Psychology, 67, 73-87.

Broomfield, L., McHugh, L., \& Reed, P. (2008a). Re-emergence of under-selected stimuli, after the extinction of over-selected stimuli in an automated match to samples procedure. Research in Developmental Disabilities, 29, 503-512.

Broomfield, L., McHugh, L., \& Reed, P. (2008b). The effect of observing response procedures on the reduction of over-selectivity in a match to sample task: Immediate but not long term benefits. Research in Developmental Disabilities, 29, 217-234.

Broomfield, L., McHugh, L., \& Reed, P. (2010). Factors impacting emergence of behavioral control by under-selected stimuli after reduction of control by over-selected stimuli. Journal of the Experimental Analysis of Behavior, 94, 125-133.

Cohen, J. (1988). Statistical power analysis for the behavioral sciences (2nd ed.). New York, NY: Academic Press.

Cohen, J. (1992). A power primer. Psychological Bulletin, 112, 155-159.

Cook, A. R., Anderson, N. A. \& Rincover, A. (1982). Stimulus over-selectivity and stimulus control: Problems and strategies. In: R. Koegel, A. Rincover and A. Egel, Editors, Educating and understanding autistic children, College-Hill Press, San Diego. 
De Houwer, J., \& Beckers, T. (2003). Secondary task difficulty modulates forward blocking in human contingency learning. The Quarterly Journal Of Experimental Psychology B: Comparative And Physiological Psychology, 56B(4), 345-357.

Denniston, J. C., Savastano, H. I., \& Miller, R. R. (2001). The extended comparator hypothesis: Learning by contiguity, responding by relative strength. In R. Mowrer \& S. Klein (Eds.), Handbook of contemporary learning theories (pp. 65-117). Hillsdale, NJ: Erlbaum.

Dickinson, A., \& Burke, J. (1996) Within compound associations mediate the retrospective revaluation of causality judgements. The Quarterly Journal of Experimental Psychology, 49, 60-80.

Dube, W. V. (2009). Stimulus over-selectivity in discrimination learning. In P. Reed (Ed.), Behavioural Theories and Interventions for Autism. New York: Nova.

Dube, W. V., Lombard, K. M., Farren, K. M., Flusser, D. S., Balsamo, L. M., \& Fowler, T. R. (1999). Eye tracking assessment of stimulus over-selectivity in individuals with mental retardation. Experimental Analysis of Human Behaviour Bulletin, 17, 8-14.

Dube, W.V., \& McIlvane, W. J. (1997). Reinforcer frequency and restricted stimulus control. Journal of the Experimental Analysis of Behaviour, 68, 303-316.

Dube, W. V., \& McIlvane, W. J. (1999). Reduction of stimulus over-selectivity with non verbal differential observing responses. Journal of Applied Behaviour Analysis, 32, 2533.

Gersten, R. M. (1983). Stimulus over-selectivity in autistic, trainable mentally retarded, and non-handicapped children: Comparative research controlling chronological (rather than mental) age. Journal of Abnormal Child Psychology, 11, 61-76. 
Gibbon, J., \& Balsam, P. D. (1981). The spread of association in time. In Locurto, C., Terrace, H. S., and Gibbon, J. (Eds.), Autoshaping and conditioning theory. New York: Academic Press.

Gibson, E., \& Reed, P. (2005). Stimulus over-selectivity in rats. Journal of Autism and Developmental Disorders, 35, 851-859.

Hedbring, C., \& Newsom, C. (1985). Visual over-selectivity: A comparison of two instructional remediation procedures with autistic children. Journal of Autism and Developmental Disorders, 15, 9-22.

Holland, P. C. (1990). Event representation in Pavlovian conditioning: Image and action. Cognition, 37, 105-131.

Howell, D. C. (1997). Statistical methods for Psychology. Boston: PSW-Kent. Kamin, L. J. (1969) Predictability, surprise, attention, and conditioning. In B. A. Cambell \& R. M. Church (Eds.), Punishment and aversive behavior. New York: Appleton-CenturyCrofts. Kaufman, M. A., \& Bolles, R. C. (1981). A nonassociative aspect of overshadowing. Bulletin of the Psychonomic Society, 18, 318-320.

Koegel, R.L., \& Schreibman, L. (1977). Teaching autistic children to respond to simultaneous multiple cues. Journal of Experimental Child Psychology, 24, 299-311.

Koegel, R. L., Schreibman, L., Britten, K., \& Laitinen, R. (1979). The effects of schedule of reinforcement on stimulus over-selectivity in autistic children. Journal of Autism and Developmental Disabilities, 9, 383-396.

Koegel, R. L., \& Wilhelm, H. (1973). Selective responding to the components of multiple visual cues by autistic children. Journal of Experimental Child Psychology, 15, 442-453.

Leader, G., Loughnane, A., McMoreland, C., \& Reed, P. (2009). The effect of stimulus salience on over-selectivity. Journal of Autism and Developmental Disorders, 39, 330338. 
Liljeholm, M., \& Balleine, B. W. (2009). Mediated conditioning versus retrospective revaluation in humans: The influence of physical and functional similarity of cues. The Quarterly Journal Of Experimental Psychology, 62(3), 470-482.

Lovaas, O. I., \& Scheribman, L. (1971). Stimulus over selectivity of autistic children in a two stimulus situation. Behaviour, Research and Therapy, 9, 305-310.

Luque, D., Flores, A., \& Vadillo, M.A. (2013). Revisiting the role of within compound associations in cue-interaction phenomena. Learning and Behavior, 41, 61-76.

Mackintosh, N. J. (1975). A theory of attention: Variations in the associability of stimuli with reinforcement. Psychological Review, 82, 276-298.Maes, E., Boddez, Y., Alfei, J. M., Krypotos, A., D'Hooge, R., De Houwer, J., \& Beckers, T. (2016). The Elusive Nature of the Blocking Effect: 15 Failures to Replicate. Journal Of Experimental Psychology: General.

Matzel, L. D., Schachtman, T. R., \& Miller, R. R. (1985). Recovery of an overshadowed association achieved by extinction of the overshadowing stimulus. Learning and Motivation, 16, 398-412.

Matzel, L. D., Schuster, K., \& Miller, R. R. (1987). Covariation in conditioned response strength between stimuli trained in compound. Animal Learning \& Behavior, 15, 439447.

Mchugh, L., \& Reed, P. (2007). Age trends in stimulus over-selectivity. Journal of the Experimental Analysis of Behaviour, 88, 369-380.

Miller, R. R., \& Matzel, L. D. (1988). The comparator hypothesis: A response rule for the expression of associations. In: G. H. Bower (Ed.), The psychology of learning and motivation. San Diego: Academic Press. 
Miller, R. R., \& Schachtman, T. R. (1985). The several roles of context at the time of retrieval. In P. D. Baslam \& a. Tomie (Eds.), Context and learning. Hillsdale, NJ: Laurence Erlbaum.

Mitchell, C. J., De Houwer, J., \& Lovibond, P. F. (2009). The propositional nature of human associative learning. Behavioral And Brain Sciences, 32(2), 183-198.

Pearce, J. M., \& Hall, G. (1980). A model for Pavlovian learning: Variations in the effectiveness of conditioned but not of unconditioned stimuli. Psychological Review, 87 (6), 532-552.

Plaisted, K., O'Riordan, M. and Baron-Cohen, S. (1998). Enhanced visual search for a conjunctive target in autism: A research note. Journal of Child Psychology and Psychiatry, 39, 777-783.

Reed, P. (2006). The effect of retention interval on stimulus over-selectivity using a matching to sample paradigm. Journal of Autism and Developmental Disorders, 36, 1115-1121.

Reed, P. (2011). Comparator mechanisms and Autistic Spectrum Conditions. In.

T.R. Schachtman \& S.R. Reilly (Eds.), Associative Learning and Conditioning: Human and Animal Applications. Oxford University Press.

Reed, P., \& Gibson, E. (2005). The effects of concurrent task load on stimulus overselectivity. Journal of Autism and Developmental Disorders, 35, 601-614.

Reed, P., Broomfield, L., McHugh, L., McCausland, A., \& Leader, G. (2009). Extinction of over-selected stimuli causes emergence of under-selected cues in higher functioning children with Autistic Spectrum Disorders. Journal of Autism and Developmental Disorders, 39, 290-298.

Reed, P., Hawthorn, R., Bolger, S., Meredith, K. \& Bishop, R. (2012). Disrupted stimulus control but not reward sensitivity in individuals with Autism Spectrum Disorders: A 
Matching Law Analysis. Journal of Autism and Developmental Disorders 42(11), 23932403.

Reed, P., Reynolds, G., \& Fermandel, L. (2012). Revaluation manipulations produce emergence of underselected stimuli following simultaneous discrimination in humans. The Quarterly Journal of Experimental Psychology, 65(7), 1345-1360.

Reed, P., Quigley, M., \& Goddard, D. (under review). Over-selectivity effects in humans decrease with increases in the amount of training.

Rescorla, R. A. (1981). Simultaneous associations. In P. Harzem \& M. D. Zeiler (Eds.), Predictability, correlation, and contiguity (pp. 47-80). New York: Wiley.

Rescorla, R.A., \& Wagner, A. R. (1972).A theory of Pavlovian conditioning: Variations in the effectiveness of reinforcement and nonreinforcement. In A. H. Black \&W. F. Prokasy (Eds.), Classical conditioning II: Current research and theory (pp. 64-99). New York: Appleton-Century-Crofts.

Revusky, S., Parker, L. A., \& Coombes, S. (1977). Flavor aversion learning: Extinction of the aversion to an interfering flavor after conditioning does not affect the aversion to the reference flavor. Behavioral \& Neural Biology, 19, 503-508.

Reynolds, G., \& Reed, P. (2011a). The strength and generality of stimulus over-selectivity in simultaneous discrimination procedures. Learning and Motivation, 42, 113-122.

Reynolds, G., \& Reed, P. (2011b). The effects of schedule of reinforcement on overselectivity. Research in Developmental Disabilities, 32, 2489-2501.

Reynolds, G., \& Reed, P. (2012). Effect of a surprising downward shift in reinforcer value on stimulus over-selectivity. Learning and Motivation, 44, 31-45.

Reynolds, G., Watts, J., \& Reed, P. (2012). Lack of evidence for inhibitory processes in overselectivity. Behavioural Processes, 89, 14-22. 
Schachtman, T. D., Kasprow, W. J., Meyer, R. C., Bourne, M. J., Hart, J. A. (1992).

Extinction of the overshadowing CS after overshadowing in conditioned taste aversion. Animal Learning \& Behavior, 20, 207-218.

Schneider, H. C., \& Salzberg, C. L. (1982). Stimulus over-selectivity in a match-to sample paradigm by severely retarded youth. Analysis and Intervention in Developmental Disabilities, 2, 273-304.

Schreibman, L., \& Lovaas, I. O. (1973). Over-selective response to social stimuli by autistic children. Journal of Abnormal Child Psychology, 1, 152-168.

Shevill, I, \& Hall, G. (2004). Retrospective revaluation effects in the conditioned suppression procedure. Quarterly Journal of Experimental Psychology, 57B, 331-347.

Sissons, H. T., Urcelay, G. P. \& Miller, R. R. (2009). Overshadowing and CS-duration: Counteraction and a reexamination of the role of within-compound associations in cue competition. Learning \& Behaviour, 37, 254-268.

Stout, S. C., \& Miller, R. R. (2007). Sometimes competing retrieval (SOCR): a formalization of the comparator hypothesis. Psychological Review, 114, 759-783.

Urcelay, G. P. (2017). Competition and facilitation in compound conditioning. Journal of Experimental Psychology: Animal Learning and Cognition, 43, 303-314.

Urcelay, G. P., \& Miller, R. R. (2009). Potentiation and overshadowing in Pavlovian fear conditioning. Journal of Experimental Psychology: Animal Behavior Processes, 35, 340356.

Urushihara, K, \& Miller, R. R. (2007). CS-duration and partial-reinforcement effects counteract overshadowing in select situations. Learning \& Behavior, 35, 201-213.

Urushihara, K, Stout, S. C., \& Miller, R. R. (2004). The basic laws of conditioning differ for elemental cues and cues trained in compound. Psychological Science, 15, 268-271. 
Running Head: STIMULUS OVER-SELECTIVITY AND CS DURATION

Van Hamme, L. J., \& Wasserman, E. A. (1994). Cue competition in causality judgements: The role of nonpresentation of compound stimulus elements. Learning and Motivation, 25, 127-151.

Wasserman, E., \& Berglan, L. R. (1998). Backward blocking and recovery from overshadowing in human causal judgement: The role of within-compound associations. The Quarterly Journal of Experimental Psychology, 51B, 121-138.

Wayland, S., \& Taplin, J. E. (1982). Nonverbal categorization in fluent and nonfluent anomic aphasics. Brain and Language, 16, 87-108.

Wayland, S., \& Taplin, J. E. (1985). Feature processing deficits following brain injury over selectivity in recognition memory for compound stimuli. Brain and Cognition, 4, 338 355.

Westbrook, R. F., Homewood, J., Horn, K., \& Clarke, J. C. (1983). Flavour-odour compound conditioning: odour potentiation and flavour-attenuation. Quarterly Journal of Experimental Psychology-B, 35, 13-33.

Wheeler, D. S., \& Miller, R. R. (2008). Determinants of cue interactions. Behavioural Processes, 78, 191-203.

Wilhelm, H., \& Lovaas, O. I. (1976). Stimulus over selectivity: A common feature in autism and mental retardation. American Journal of Mental Deficiency, 81, 26-31. 
Running Head: STIMULUS OVER-SELECTIVITY AND CS DURATION

Exp Phase Procedure

Exp 1 Training Phase AB+ vs. CD-; EF+ vs. GH-

Duration of each trial depends on group: $2 \mathrm{~s}, 5 \mathrm{~s}$ or $10 \mathrm{~s}$

Phase ends when ten consecutive correct responses are given in both tasks

Test Phase

A vs. C; A vs. D; B vs. C; B vs. D;

Evs. G; E vs. H; F vs. G; F vs. H

Five trials of each combination presented randomly

Exp 2 Training Phase AB+ vs. CD-; EF+ vs. GH-

Duration of each trial depends on group: $2 \mathrm{~s}$ or $10 \mathrm{~s}$

Phase ends when ten consecutive correct responses are given in both tasks

Test Phase

A vs. C; A vs. D; B vs. C; B vs. D;

Evs. G; E vs. H; F vs. G; F vs. H

Five trials of each combination presented randomly

Revaluation Over-selected stimulus from AB(-) vs. Novel stimulus(+)

Phase Over-selected stimulus from EF(-) vs. Novel stimulus(+)

Phase ends when ten consecutive correct responses are given in both tasks

Retesting Phase A vs. C; A vs. D; B vs. C; B vs. D;

E vs. G; E vs. H; F vs. G; F vs. H

Five trials of each combination presented randomly

Exp 3 Training Phase AB+ vs. CD-; EF+ vs. GH- 
Groups Consistent-R1 and Consistent R-2 receive 18 trials of each task. Duration of trials: $2 \mathrm{~s}$

Group Varied receive all possible variants of the two tasks (i.e.,

$$
\begin{aligned}
& \mathrm{AB}+\mathrm{CD}-, \mathrm{AE}+\mathrm{CD}-, \mathrm{AF}+\mathrm{CD}-, \mathrm{AB}+\mathrm{GH}-, \mathrm{AE}+\mathrm{GH}-, \mathrm{AF}+ \\
& \mathrm{GH}-, \mathrm{AB}+\mathrm{CG}-, \mathrm{AE}+\mathrm{CG}-, \mathrm{AF}+\mathrm{CG}-, \mathrm{AB}+\mathrm{CH}-, \mathrm{AE}+\mathrm{CH}-, \\
& \mathrm{AF}+\mathrm{CH}-, \mathrm{AB}+\mathrm{DG}-, \mathrm{AE}+, \mathrm{DG}-, \mathrm{AF}+, \mathrm{DG}-, \mathrm{AB}+\mathrm{DH}-, \mathrm{AE}+ \\
& \mathrm{DH}-, \mathrm{AF}+\mathrm{DH}-, \mathrm{BE}+\mathrm{CD}-, \mathrm{BF}+\mathrm{CD}-, \mathrm{BE}+\mathrm{GH}-, \mathrm{BF}+\mathrm{GH}-, \mathrm{BE}+ \\
& \mathrm{CG}-, \mathrm{BF}+\mathrm{CG}-, \mathrm{BE}+\mathrm{CH}-, \mathrm{BF}+\mathrm{CH}-, \mathrm{BE}+\mathrm{DG}-, \mathrm{BF}+\mathrm{DG}-, \mathrm{BE}+ \\
& \mathrm{DH}-, \mathrm{BF}+\mathrm{DH}-, \mathrm{EF}+\mathrm{CD}-, \mathrm{EF}+\mathrm{GH}-, \mathrm{EF}+\mathrm{CG}-, \mathrm{EF}+\mathrm{CH}-, \mathrm{EF}+ \\
& \mathrm{DG}-, \mathrm{EF}+\mathrm{DH}-)(36 \text { trials in total}) . \text { Duration of trials: } 2 \mathrm{~s}
\end{aligned}
$$

Test Phase

A vs. C; A vs. D; B vs. C; B vs. D;

E vs. G; E vs. H; F vs. G; F vs. H

Five trials of each combination presented randomly

Revaluation Groups Consistent-R2 and Varied:

Phase

Over-selected stimulus from AB(-) vs. Novel stimulus(+)

Over-selected stimulus from EF(-) vs. Novel stimulus(+)

Phase ends when ten consecutive correct responses are given in both tasks

Group Consistent-R1:

Over-selected stimulus from $\mathrm{AB}(-)$ vs. Novel stimulus(+)

Phase ends when ten consecutive correct responses are given

Retesting Phase A vs. C; A vs. D; B vs. C; B vs. D;

E vs. G; E vs. H; F vs. G; F vs. H

Five trials of each combination presented randomly

Table 1. Tabulated form of the procedures. 

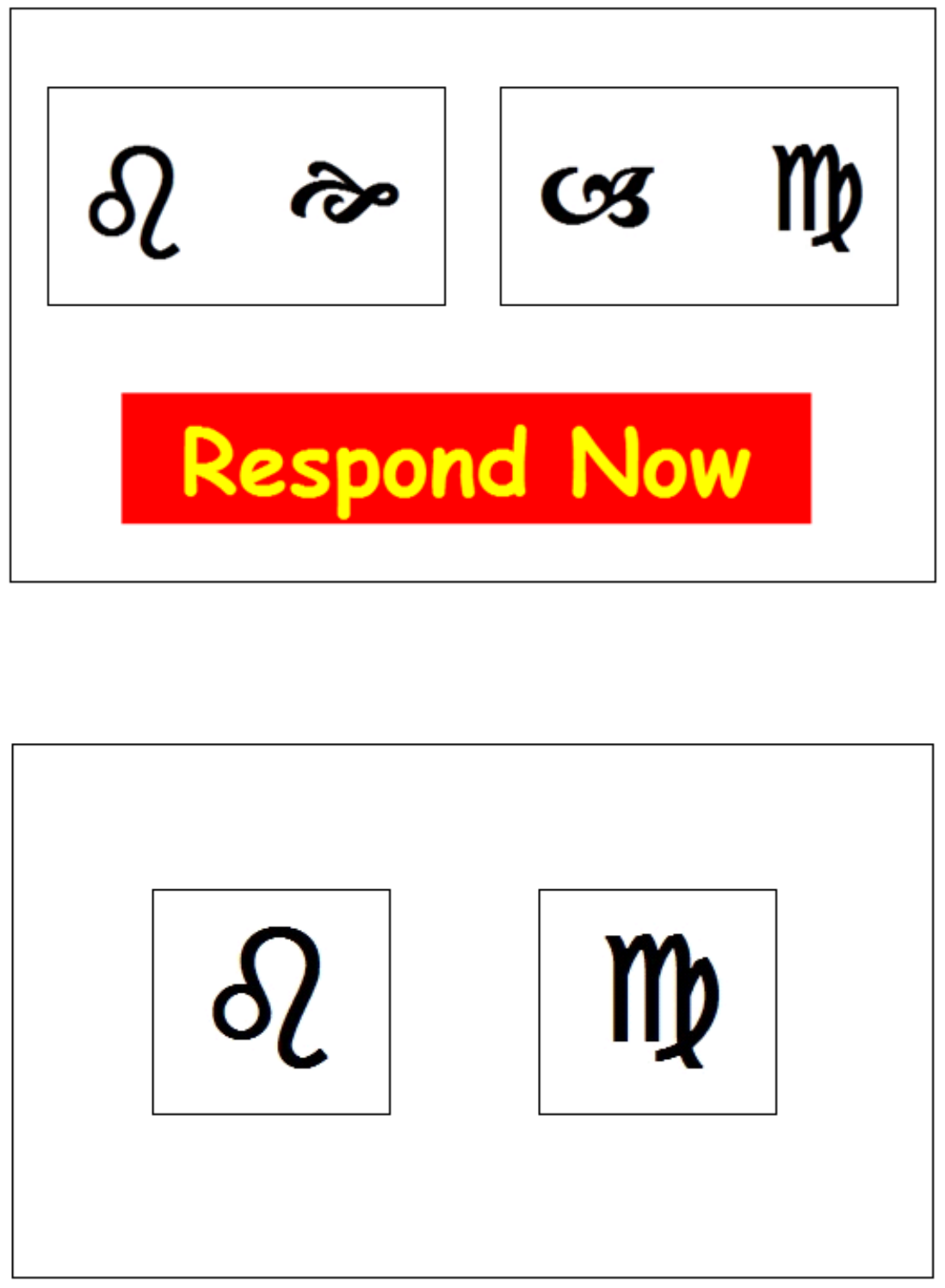

Fig. 1. An example of the compound stimuli used during the training phase, followed by an example of the elemental stimuli used during the testing phase. 


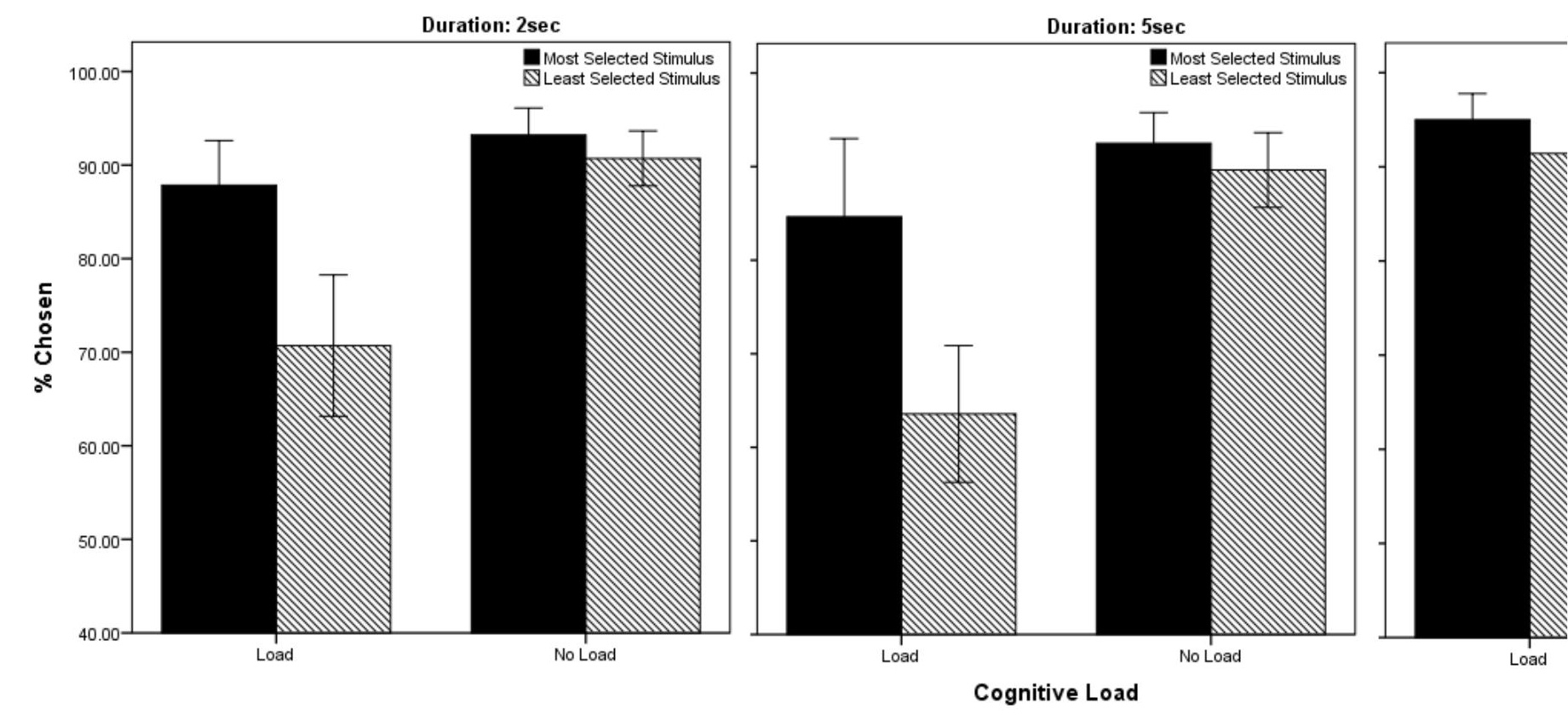

Fig. 2. Experiment 1. Group mean levels of over-selectivity in the each stimulus duration group $(2 \mathrm{sec}, 5 \mathrm{sec}, 10 \mathrm{sec})$ when receiving a cognitive load or not receiving a cognitive load $($ error bars $=\mathrm{SEM})$ 


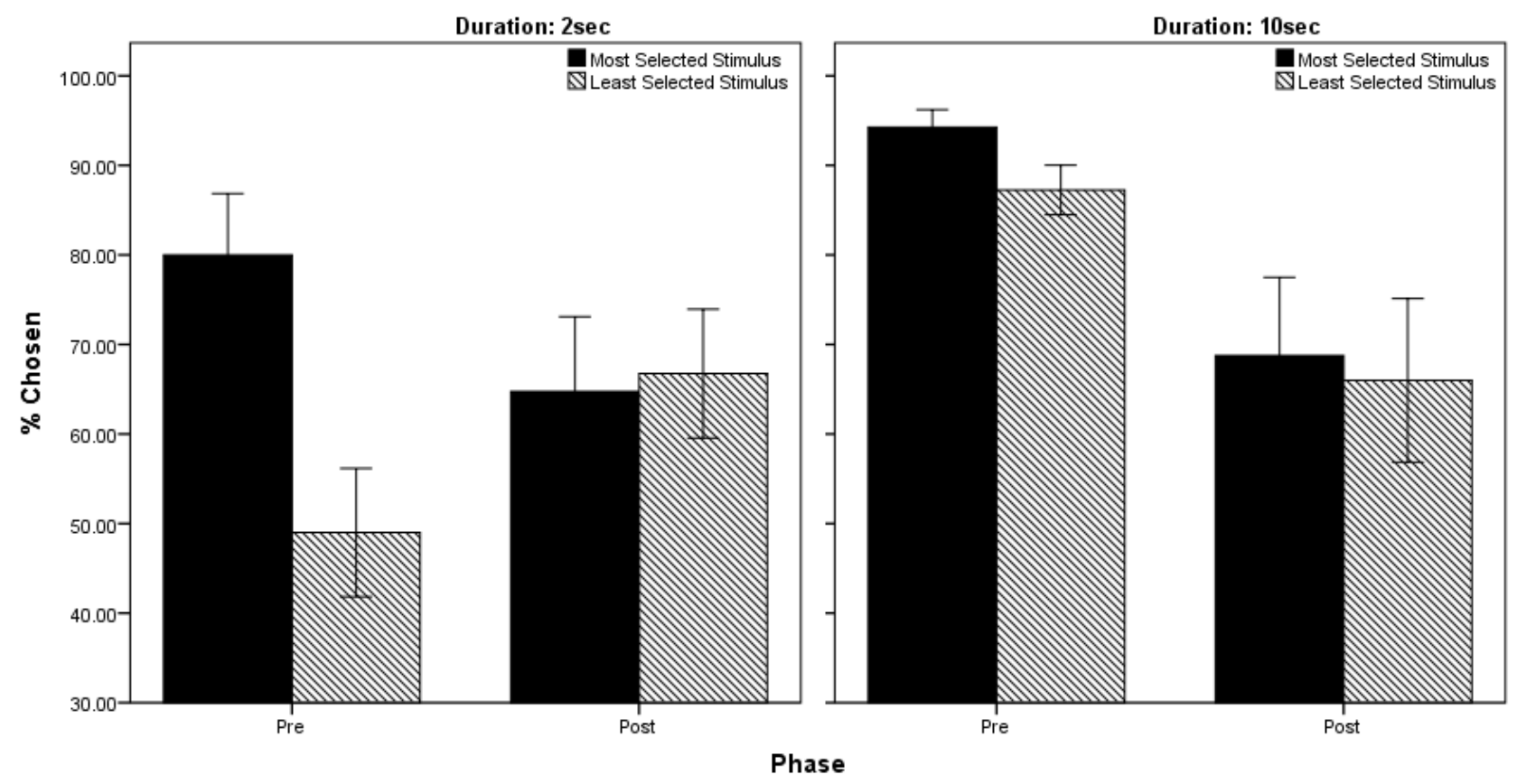

Fig. 3. Experiment 2. Group mean levels of over-selectivity in each stimulus duration group $(2 \mathrm{sec}, 10 \mathrm{sec})$ pre-revaluation and post- revaluation (error bars $=\mathrm{SEM})$ 


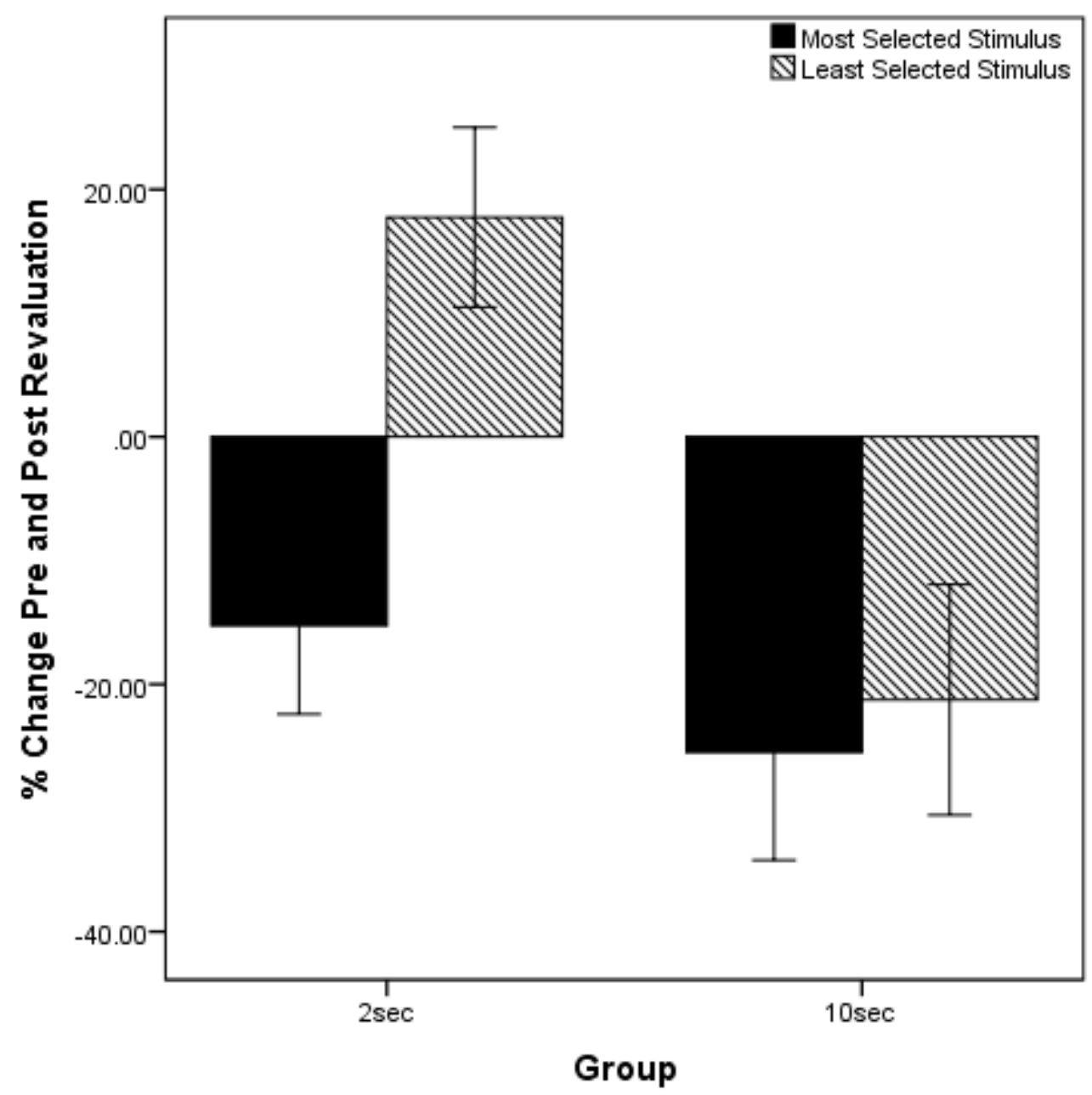

Fig. 4. Experiment 2. Group mean percentage change of stimulus selection pre and post revaluation in each stimulus duration group $(2 \mathrm{sec}, 10 \mathrm{sec})($ error bars $=\mathrm{SEM})$ 

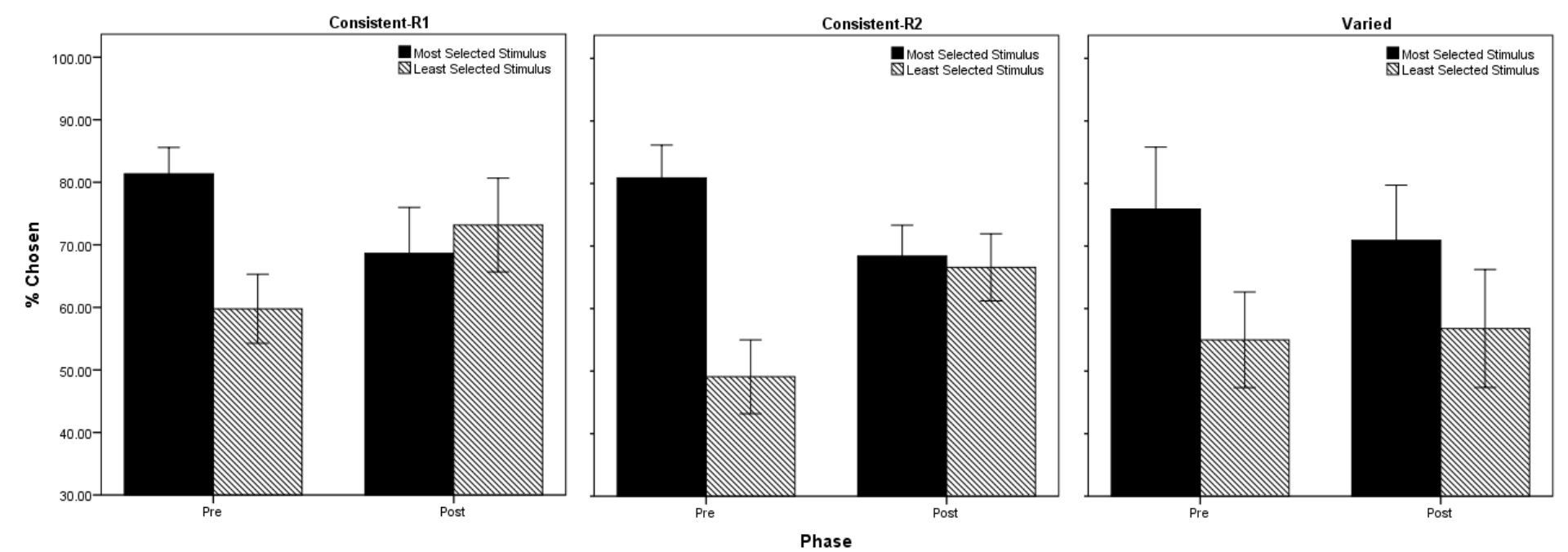

Fig. 5. Experiment 3. Group mean levels of over-selectivity in each group (Consistent-R1, Consistent-R2, Varied) pre- revaluation and post- revaluation (error bars $=$ SEM) 


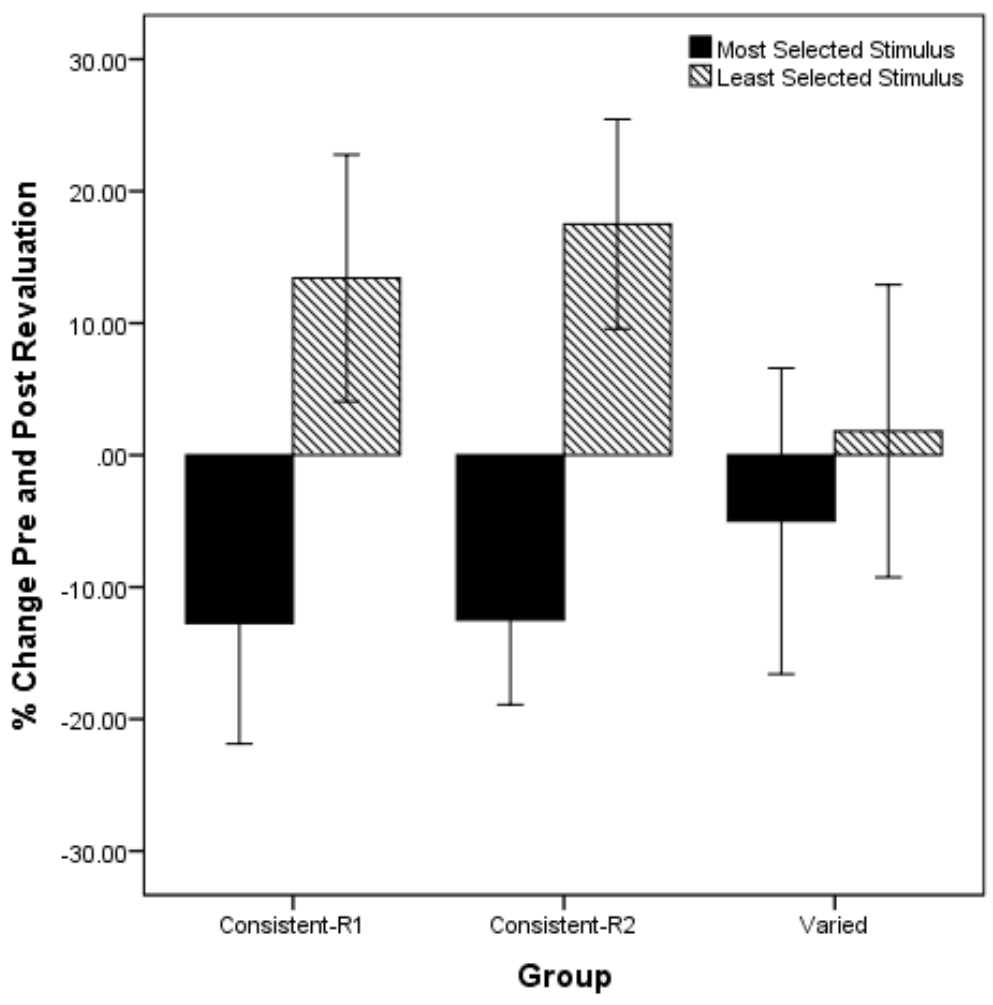

Fig. 6. Experiment 3. Group mean percentage change of stimulus selection pre- and postrevaluation in each group (Consistent-R1, Consistent-R2, Varied) $($ error bars $=$ SEM) 


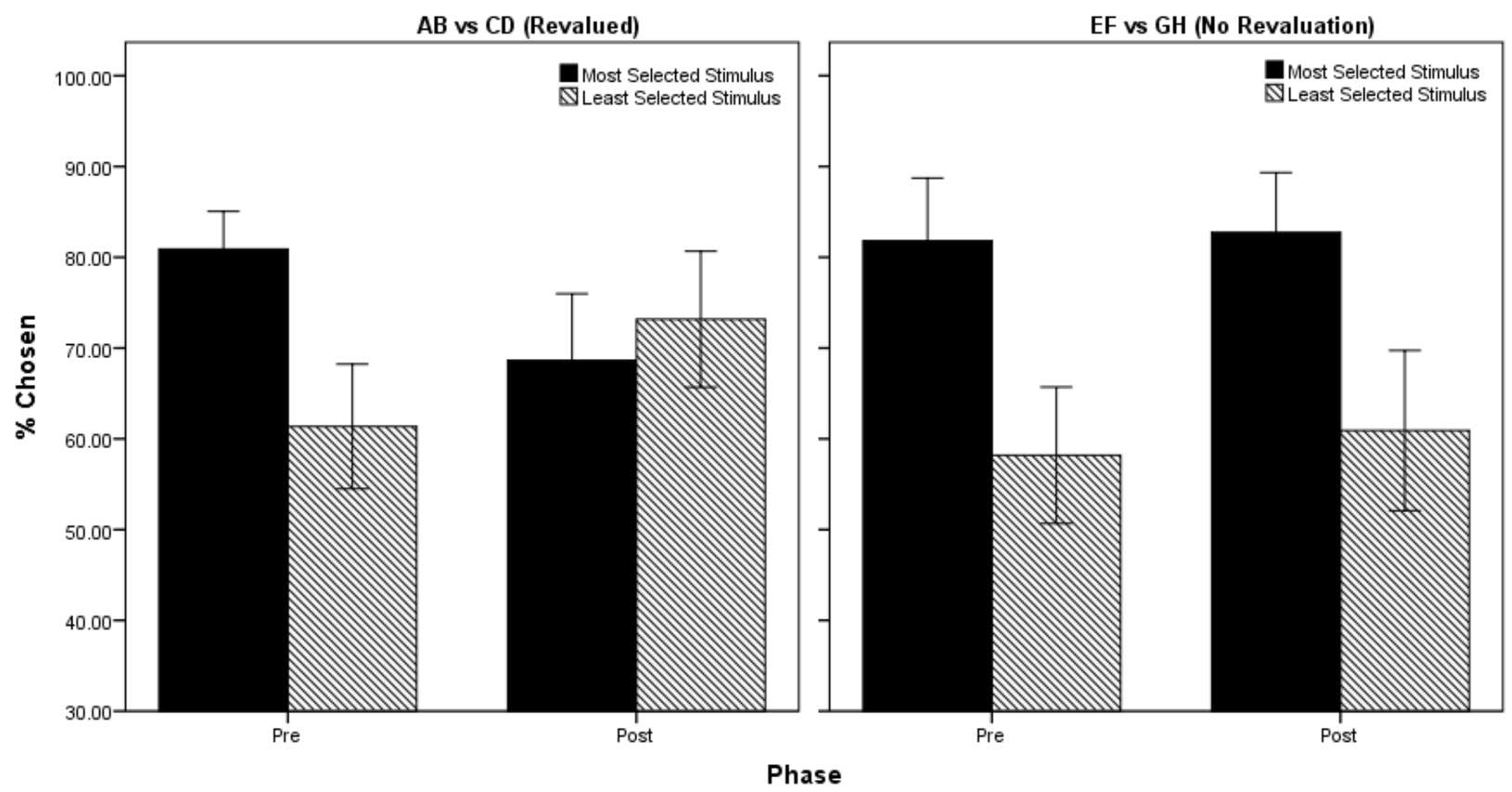

Fig. 7. Experiment 3. Mean levels of over-selectivity in the Consistent-R1 group at prerevaluation and post- revaluation in each discrimination task ( $\mathrm{AB}$ vs $\mathrm{CD}, \mathrm{EF}$ vs $\mathrm{GH}$ ) whereby $\mathrm{AB}$ received revaluation and $\mathrm{EF}$ was not revalued (error bars $=\mathrm{SEM}$ ) 


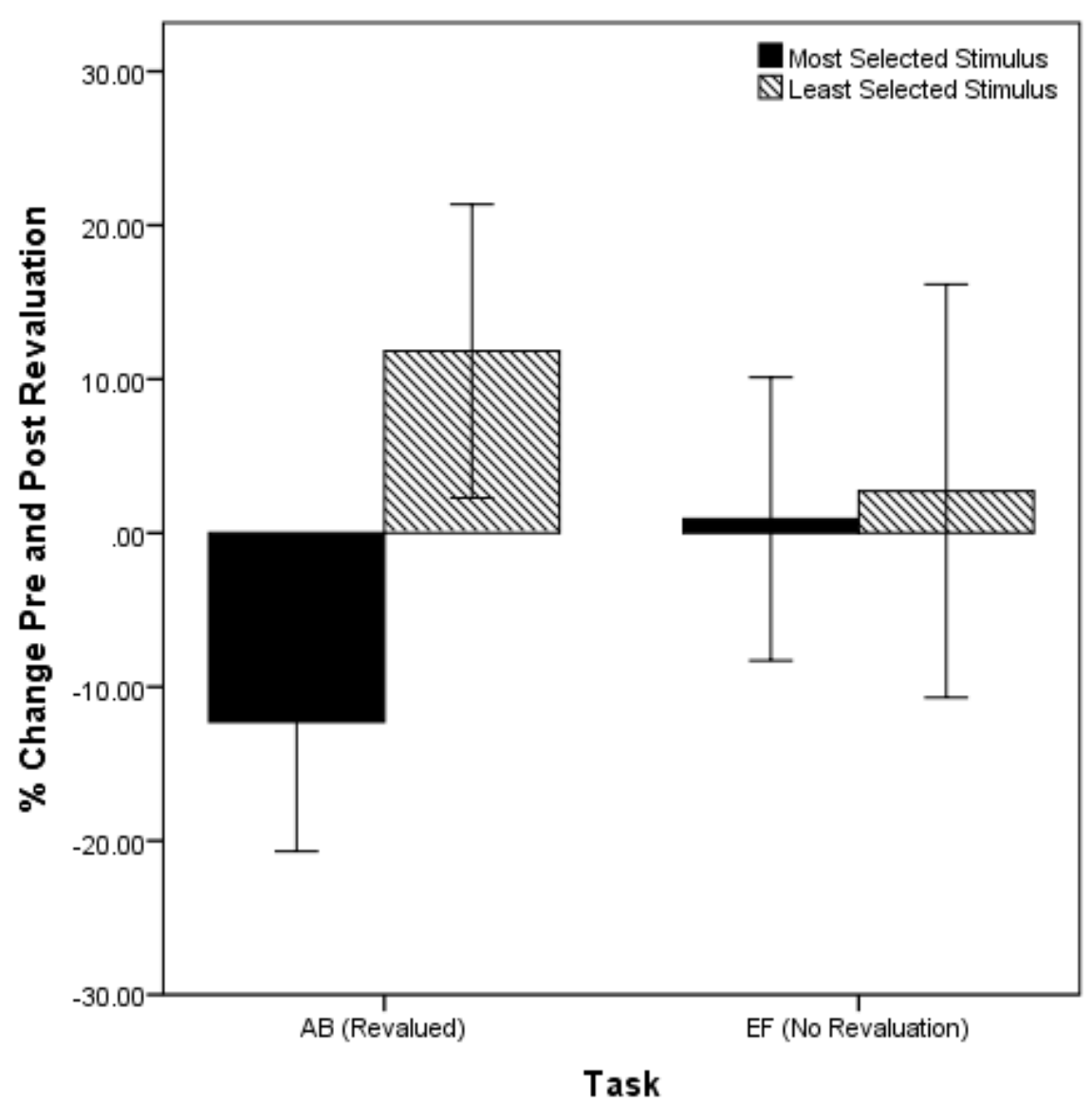

Fig. 8. Experiment 3. Mean percentage change of stimulus selection pre- and post-

revaluation in the Consistent-R1 in each discrimination task (AB vs $\mathrm{CD}$, EF vs $\mathrm{GH}$ ) whereby $\mathrm{AB}$ received revaluation and $\mathrm{EF}$ was not revalued (error bars $=\mathrm{SEM}$ ) 